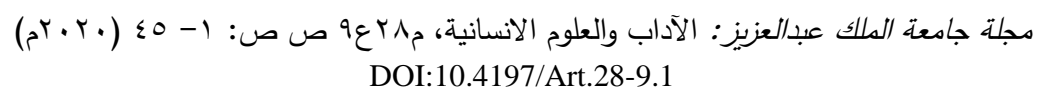

\title{
الإسهام النسبى لأبعاد الحكمة فى التنبؤ باليقظة العقلية ومهارات فعالية الحياة لدى طالبات جامعة القصيم
}

\author{
د. جوهرة صالح المرشود \\ أستاذ مشارك الصحة النفسية \\ كلية التربية - جامعتة الإمام عبدالحمن بن فيصل
}

مستخلص. هدف هذا البحث إلى التعرف على العلاقة بين أبعاد الحكمة واليقظة العقلية، والتعرف على العلاقة بين أبعاد الحكمة ومهارات فعالية الحياة لدى طالبات جامعة القصيم، كذلك الكثف عن الفروق فى الحكمة واليقظة

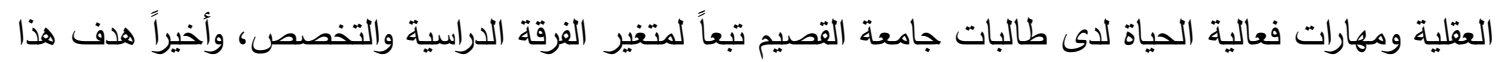

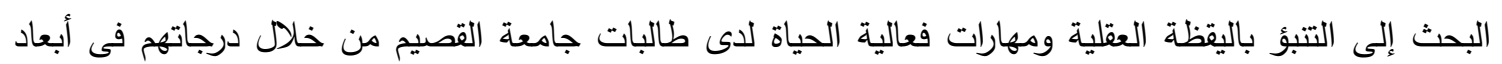
الحكمة.

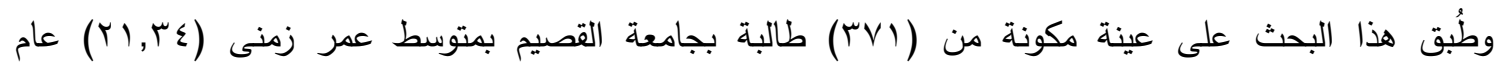
وبإنحراف معيارى قدره (9., (Y). واستخدمت الباحثة مقياس الحكمة ومقياس اليقظة العقلية من إعدادها، كما

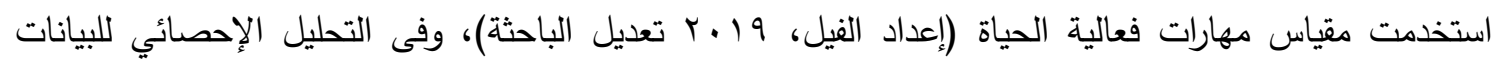

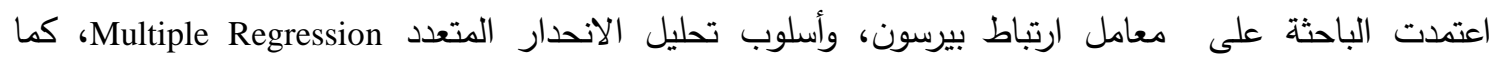

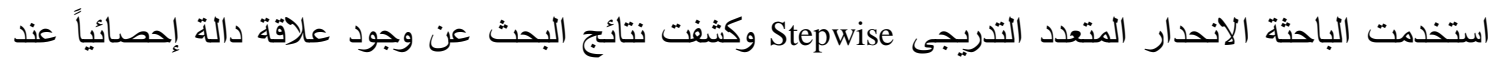

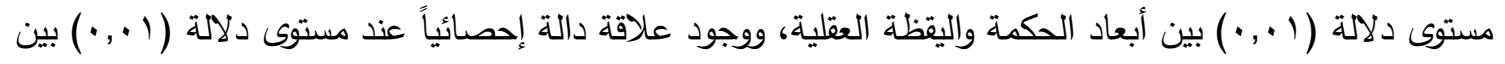

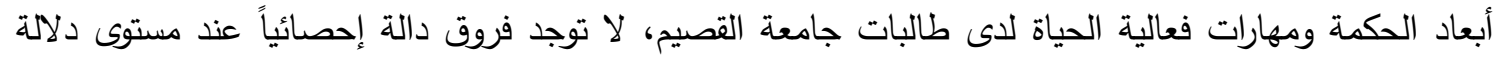

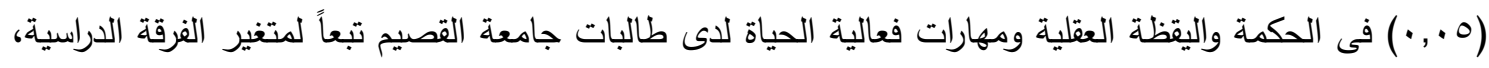

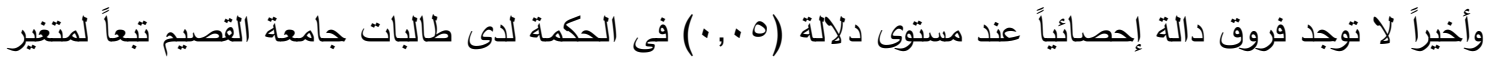

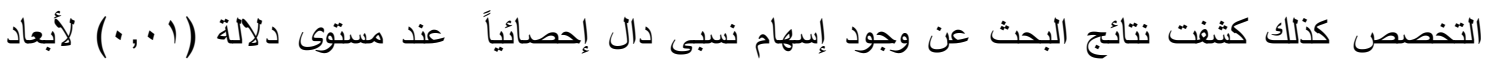
الحكمة فى التتبؤ باليقظة العقلية ومهارات فعالية الحياة لدى طلاب جامعة اليقات القصيم. 
وأوصى هذا البحث بالعديد من التوصيات منها تقديم ورش لطلاب الجامعة تختص بتدريبهم على الحكمة واليقظة العقلية ومهارات فعالية الحياة، وإعداد برامج إرشادية وتدريبية لتتمية الحكمة واليقظة العقلية ومهارات فعالية الحياة

$$
\text { لاى طلاب الجامعة. }
$$

الكلمات المفتاحية: الحكمة - اليقظة العقلية - مهارات فعالية الحياة.

أشكال التفكير ، وكذلك تعد مهارة لحل المشكلات حينما يواجه الفرد أمورًا صعبةً وغامضةً في الحياة

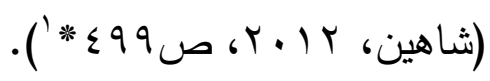
وعرف أيّوب (Y ( • Y، ص V • Y) الحكمة بأنها فهم الفرد العميق لذاته وللآخرين والاستخدام النشط للمعرفة، والقدرة على التعلم من الأفكار والبيئة، مع حدة الذهن Perspicacity، والبصيرة Insight والقدرة على إصدار الأحكام Judgment كذلك عرف Massanelli (2016, P49 الحكمة بأنها سمة شخصية أو فضيلة تتعلق بالذكاء والمعالجة

المعرفية.

ولا يعتمد تطور الحكمة فقط على الدوافع والجهود اللازمة لاكتساب المعرفة عن الحياة، ولكن أيضًا على مدى توفر مرشد حكيم يمكن من خلاله أن يسعى الفرد للحصول على النصيحة فى التعامل مع (Jordan, مروره بتقلبات وتغيرات خلال الحياة

واقترح بعض العلماء من معهد ماكس بلانك أن الحكمة مرتبطة بعوامل داخلية تتبع من داخل الفرد مثل: الإدراك والإبداع والانفتاح، وعوامل خارجية تتعلق بالخبرة مثل: الإرشاد والخبرة فى مجالات

'ـ أُعد هذا البحث وفقًا لدليل الجمعية الأمريكية لعلم النفس ( APA ) Style of the Publication Manual of the American .Psychological Association (6th Edition)

\section{المقدمة}

قال الله تعالى جل شأنه فى كتابه الحكيم "يؤَّتي

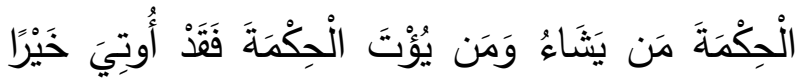

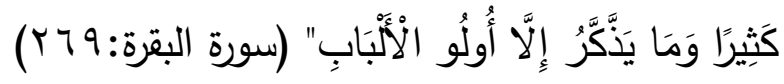
تُعد الحكمة أحد أركان الأداء العقلى النموذجى للفرد حيث تميزه عن غيره من أقرانه بما تشمله من تمكين الفرد من الاستبصار والتأمل ومعرفة الذات وفهم الغير، كذلك تساعده على حسن إتخاذ القرارات وإصدار أحكام عقلانية على الأحداث، وتتظيم إنفعالاته والانفتاح العقلى على المجتمع والأخرين كذلك تمكنها من التعامل مع المواقف الحياتية بشكل فعال؛ ولذا فالحكمة كذدرة عقلية عليا ترتبط بالعديد من المتغيرات وتؤثر فيها وتتأثر بها. وتعد الحكمة من المتغيرات المعرفية التى لها الدور المحورى فى تشكيل فاعلية الفرد، وهى من أكثر الحالات المستهدفة للنمو الإنسانى لسببين، أولاً: أنها تمثل أعلى مستوى من المعرفة بالأهداف والوسائل فى الحياة التى توصل إليها تحليل الفلاسفة والأنثربولوجيين، ثانيًا: أنها تتميز بالعمومية لأنها نتيجة لمستوى عال من الجريد الذى يسمح بالتتوع، وبهذا المعنى فإنها تجمع العالمية مع الخصوصية

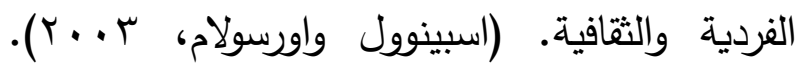
والحكمة تدرس على أنها سمة شخصية أو شكل من 
واحد. وتمثل اليقظة العقلية هذه العملية لحظة بلحظة. ويشار إلى هذه المكونات بـ (IAA) وتعنى

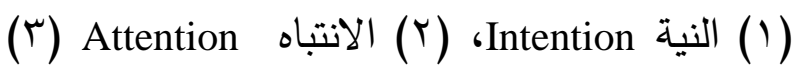
(Shapiro, Sh, Carlson, L, Attitude الاتجاه -Astin, J\& Freedman, B, 2006) وتكمن أهمية ممارسة اليقظة العقلية فى أنها تساعد الفرد على رؤية وقبول الأشياء كما هى، وليس كما نتمنى أن تكون، على سبيل المثال، يمكن أن تساعدنا فى التعامل مع حتمية المرض أو حتى الموت، كما تساعد الفرد على تخفيف انشغاله مع الذات ومع القلق، كذلك تساعده على رؤية الشخص الآخر بشكل أوضح، لذلك نحن لا ننشخل كثيرًا فى إدانة الشخص الآخر الذى يسبب لنا الإزعاج، وتمكنه من عدم اتخاذ الأمور والتعامل معها بصفة شخصية، لذلك، يمكننا أن ندرك سلوك الثخص الآخر، حتى لو كان مزعجًا لنا بأنها ليس حقيقةً عنا، كما تساعد الفرد على التعلم فى الأوقات الصعبة وليس محاولة تجنب هذه الأوقات والتهرب منها، لذلك يمكننا أن نستجيب بدقة بدلاً من الرد تلقائيًا أو الغضب. (Siegel, R. 2014). ويتمكن الفرد اليقظ عقليًا من تمييز المعلومات منذ بدء عرضها ثم يعالجها من خلال التفسير الواعى لها؛ لأن الفرد اليقظ عقليًا يصنف المدخلات المعرفية ثم يعالجها؛ حتى يتمكن من السيطرة عليها ضمن السياق المخصص لها (أسمهان يونس، $\cdot(r \cdot 10$
معينة، والسياقات التجريبية مثل: السن، والتعليم، والعمل (Mickler \& Staudinger 2008). كما يرتبط اكتساب الحكمة بعلاقات شخصية طويلة الأمد بين كل من المعلم والمتعلم. أى أن وجود وغياب التوجيه والإرشاد (على سبيل المثال، شبكات الدعم الاجتماعى والأسرى) يمكن أن يؤثر على فهم (OH, الطلاب واكتسابهم للحكمة بعد مرور الزمن .2013, P14) وكشفت نتائج دراسة (2012) Hill\& Updegraff عن وجود علاقة دالة إحصائياً بين التظيم الانفعالى كأحد أبعاد الحكمة واليقظة العقلية. وترى الباحثة أن الطالبة التى لديها مستوى مرتفع من الحكمة سيكون لايها من المفترض أن يكون لديها مستوى مرتفع من من ومتميز من الملاحظة الآنية والتعامل الواعلى والتأملى كما ستتحو إلى قبول الأثياء كما هى وسوف تأجل الحكم عليها وهذه الأبعاد: (الملاحظة الآنية - التعامل الواعلى والتأملى - استبعاد الحكم) تمثل مفردات اليقظة العقلية لدى الطالبة.

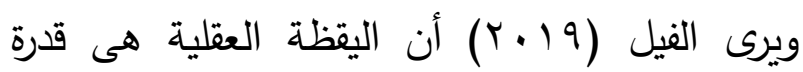
الفرد الفائقة على استحضار كامل انتباهه وتركيزه ووعيه لكل ما يحدث فى اللحظة الآنية دون غيرها مع عدم انشغاله بتقييم ما يحدث أو ربطه بما قد يحدث أو بما حدث. ويوجد ثلاثة مكونات لليقظة العقلية، وهذه المكونات ليست مراحل منفصلة بل هى جوانب متكاملة ومتداخلة من عملية دورية واحدة تحدث فى وقت 
قاسم مشترك بين قبول المواقف وتأجيل الحكم عليها والانتباه المستمر واليقظ للعلاقات بين عناصر الموقف ومقدار تمتع الطالبة بالحكمة.

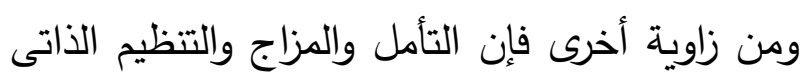
للإنفعالات والخبرة كأبعاد للحكمة قد يكون من شأنهح أن يؤثروا فى مهارة إدارة الوقت لادى الطالبة، وإدارة

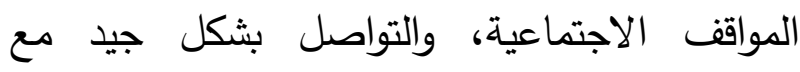
الناس، والثقة بالنفس، وقيادة المهام والمبادرة النشطة والتأثير فى الآخرين، والقدرة على حلى وفئل المشكلات الاجتماعية، وهذه المهارات تعكس بعض الاحرين ولغرة مهارات

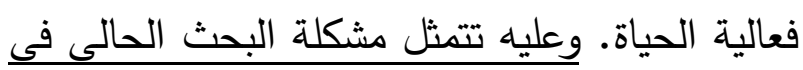
الأسئلة الآتية:-

س ا - مـا نـوع ودرجـة العلاقـة بين الحكمـة واليقظـة العقلية لدى طالبات جامعة القصيخ؟ س r - مـا نوع ودرجة العلاقة بين الحكمة ومهارات

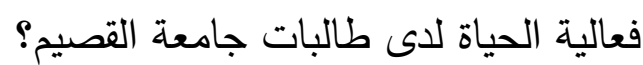

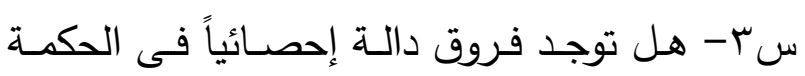
واليقظة العقلية ومهارات فعالية الحياة لدى طالبات جامعــة القصــيم تبعــاً لمتغيـر الفرقـــة الدراســية والتخصص؟ س ع - ما إمكانية التتبؤ باليقظة العقلية لدى طالبات جامعة القصيم من خلال درجاتهم فى الحكمة؟

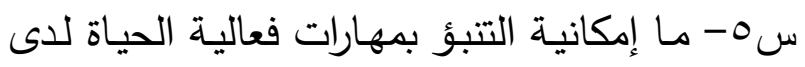

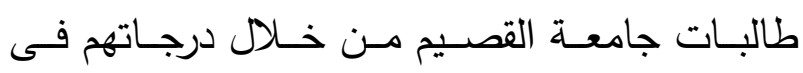

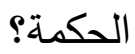

وترى الباحثة أن اليقظة العقلية قد يكون من شأنها

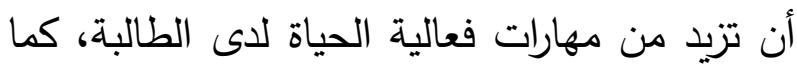

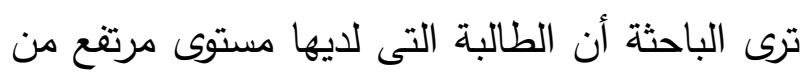

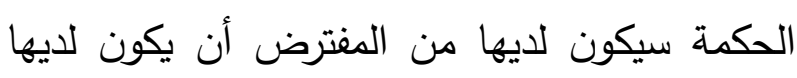

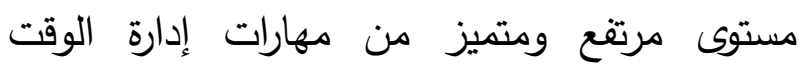
ودافعية الإنجاز المرونة العقلية وقيادة المهمة ملهير والمبادرة النشطة والثقة بالنفس وهذه المهارات تمثل مهارات فعالية الحياة لدى الطالبة. حيث ينظر إلى فعالية الحياة على أنها الطريقة التى يفكر ويعمل ويستجيب بها الفرد فى مجموعة متنوعة من الحالات والمواقف. وتشمل مهارات فعالية الحياة إدارة الوقت، والكفاءة الاجتماعية، ودافعية الإنجاز ،

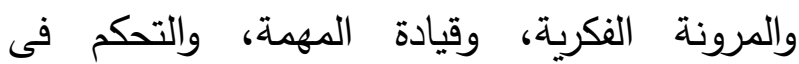
الوجدانات والمبادرة الفعالة. وترتبط فعالية الحياة ارتباطًا وثيقًا بالنجاح فى الحياة. (Neill, 2008)

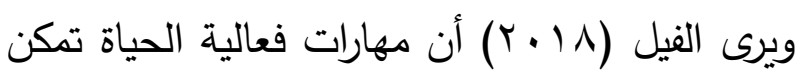
الفرد من أن يكون ماهرًا ومنتجًا، كما تساعده على حسن التصرف فى المواقف المختلفة التى تواجهه، كذلك تساعده على حل المشكلات التى تواجهه فى مختلف جوانب حياته الثخصية والأكاديمية.

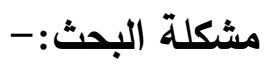

يتضح مما تقدم أن الحكمة بأبعادها الخمسة

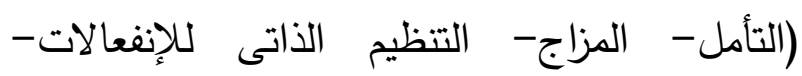
الخبرة- الإنفتاح العقلى) قد تؤثر وتتأثر بمقدار انتباه

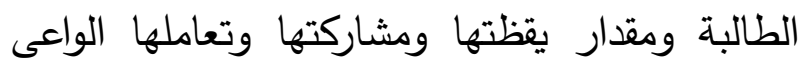
فى المواقف المختلفة التى تعايشها، كما يبدو وجود 
ع- قد يُثير هذا البحث العديد من الأفكار البحثية الجديدة والمرتبطة بمتغيراته لاى الباحثين فى العلوم

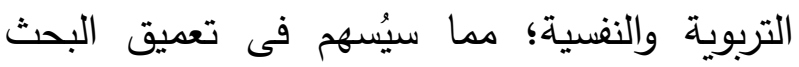
التربوى والسيكولوجى المرتبط بالحكمة واليقظة العقلية ومهارات فعالية الحياة.

0- تقدم نتائج البحث معلومات علمية مُفيدة حول طبيعة العلاقة بين الحكمة واليقظة العقلية ومهارات فعالية الحياة للى طالبات الجامعة كفئة مهمة ينبغى رعايتها والاستثمار فيها مما يساعد على تحقيق

$$
\begin{aligned}
& \text { الرقى والازدهار للشباب السعودى. } \\
& \text { مصطلحات البحث:- }
\end{aligned}
$$

$$
\text { Wisdom - }
$$

تُعرفها الباحثة بأنها قدرة الطالبة على معرفة ذاتها

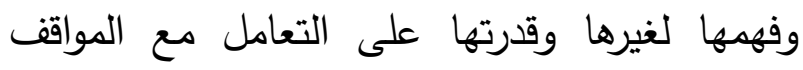
الحياتية بشكل فعال، كذلك قدرتها على إصدار الأحكام العقلانية على الأحداث.

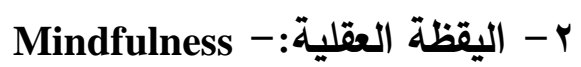

تُعرفها الباحثة بأنها مجموعة مؤشرات سلوكية تتعلق بمقدار قوة واستمراية الانتباه والملاحظة الآنية

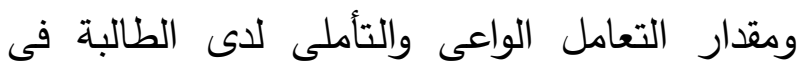

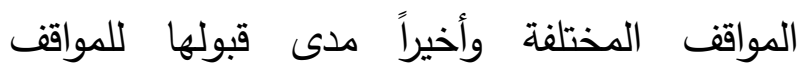
المختلفة واستبعاد الحكم الفورى عليها. Life Effectiveness - - مهارات فعالية الحياة Skills تُعرفها الباحثة بأنها مجموعة من المهارات التى تساعد الطالبة على النجاح فى حياتها الأكاديمية والاجتماعية وتشمل مهارات إدارة الوقت، والكفاءة

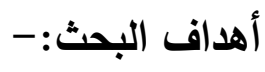

1- التعرف على العلاقة بين الحكمة واليقظة العقلية لاى طالبات جامعة القصيم. r- التعرف على العلاقة بين الحكمة ومهارات فعالية الحياة لدى طالبات جامعة القصيم. r- الكثف عن الفروق فى الحكمة واليقظة العقلية ومهارات فعالية الحياة لاى طالبات جامعة القصيم تبعاً لمتغير الفرقة الدراسية والتخصص.

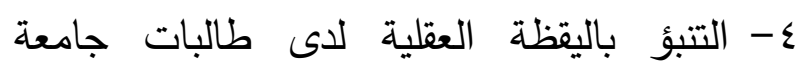
القصيم من خلال درجاتهم فى الحكمة. - التنبؤ بمهارات فعالية الحياة لاى طالبات جامعة القصيم من خلال درجاتهم فى الحكمة. أهمية البحث:- المن 1- يُعد هذا البحث بمثابة استجابة لتوصيات العديد

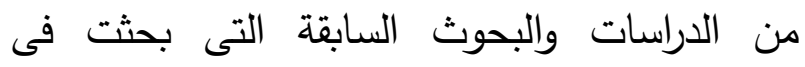
الحكمة واليقظة العقلية ومهارات فعالية الحياة

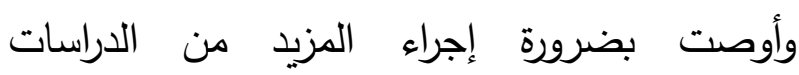
لاستجلاء هذه المتغيرات وكثف علاقاتها بالمتغيرات الأخرى وترسيخها فى البيئة العربية. r- حداثة المتغيرات الثلاثة التى يتتاولها البحث لـثئه الحالى فى البيئة العربية وفى البيئة السعودية بصفة

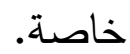
r- قد يخدم مقياس الحكمة الذى تم إعداده فى هذا البحث الباحثين فى العلوم التربوية والنفسية كأداة صادقة وثابتة لقياسها. 
في حين عرف Ardelt's (2004) الحكمة بأنها نوع مثالى من السمات التى تجمع بين الجوانب (المعرفية، والتأملية، والعاطفية) للشخصية. وعرفها Rowley (2006) بأنها قدرة الفرد على تمييز المعلومات التى يحصل عليها، واختيار مـا يساهم في سعادته. كما عرف Baltes \& Smith $(2008,58$ (الحكمة بأنها خلاصة المعرفة الخبراتية بالحقائق مما يجعل الفرد قادرًا على الحكم الجيد على الأمور الجوهرية فى الحياة التى يحيط بها الثك. ومما تقدم ترى الباحثة أن الحكمة هى قدرة الطالبة على معرفة ذاتها وفهمها لغيرها وقدرتها على التعامل مع المواقف الحياتية بشكل فعال، كذلك قدرتها على إصدار الأحكام العقلانية على الأحداث.

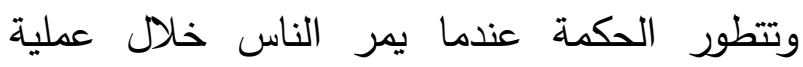
"التعلم من الحياة"، حيث يتأملون ويندمجون ويطبقون الدروس التى تعلموها، داخل وخارج الفصل، وداخل وخارج الحرم الجامعى على حياتهم. وهناك شروط لتهاج ثلاثة تسهل مباشرةً تطوير الحكمة، وهذه الشروط

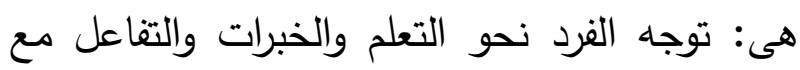
الآخرين. وتحدث جميع هذه الظروف في بيئة معينة فى سياق يؤثر على توجه الفرد نحو التعلم والتطوير . ويوفر هذا السياق الخبرات. ويشير التوجه نحو التعلم إلى الاتجاه، ومستوى المشاركة، وإمكانية اكتساب المعرفة عندما يتعامل الفرد مع الأنشطة والآخرين.

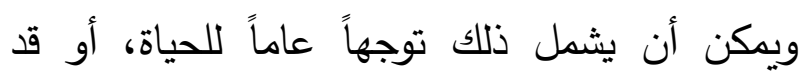

الاجتماعية، والدافعية الإنجاز، والمرونة العقلية، وقيادة المهمة، والتحكم فى الوجدانات، والثقة بالنفس،

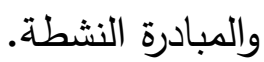
الإطار النظري والدراسات السابقة:أولاً: الحكمة:-- الاطنار الطري تعد الحكمة واحدة من أقدم الموضوعات فى تاريخ التعليم والتدريس. وأشار بيان كونفوشيوس الثهير

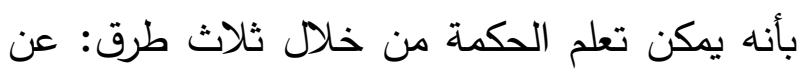

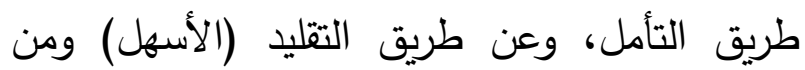

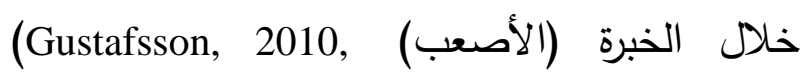
. .P30) ووفقًا لقاموس أكسفورد للغة الإنجليزية، يتم تعريف الحكمة من خلال ثلاث طرق مختلفة: التعريف الأول هو القدرة على الحكم الصحيح على الأمور المرتبطة بالحياة والسلوك. والتعريف الثانى هو عو الثى الثور

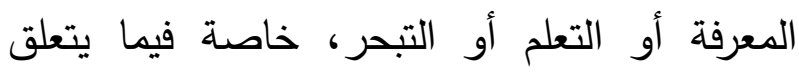
بالفلسفة أو العلوم. والتعريف الثالث هو فهم ما هو اولئه

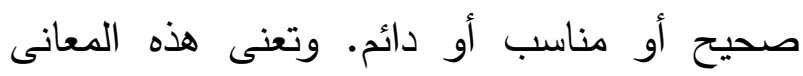

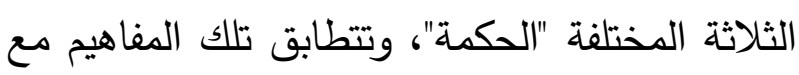
ثلاث بنيات للأدب والتى تركز على مفهوم الحكمة،

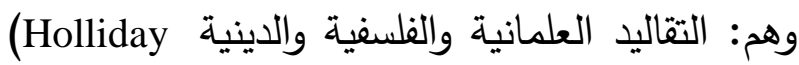
.\& Chandler, 1986) وعرف Sternberg (2001) الحكمة بأنها نتيجة الذكاء والإبداع مع القيم التى تركز على الصالح

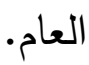


يختلف باختلاف المجالات أو المواقف المحددة، الأشخاص المؤثرين. وتشير البيئة إلى الإعدادات

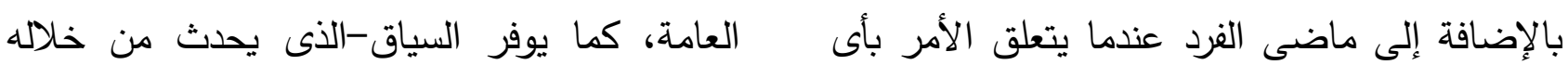

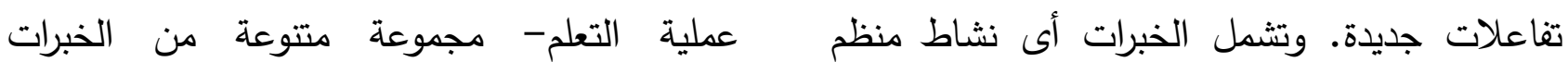
وغير منظم. وتشمل التفاعلات مع الآخرين جميع والتفاعلات مع الفرد فى مجموعات مختلفة لإنتاج

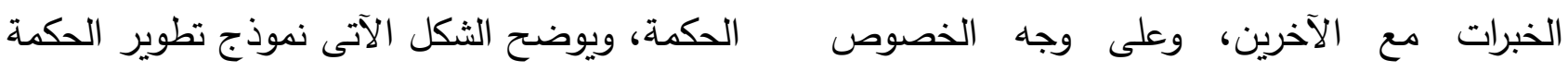
العلاقات مثل: الصداقات والأسرة والخبرات مع عند براون.

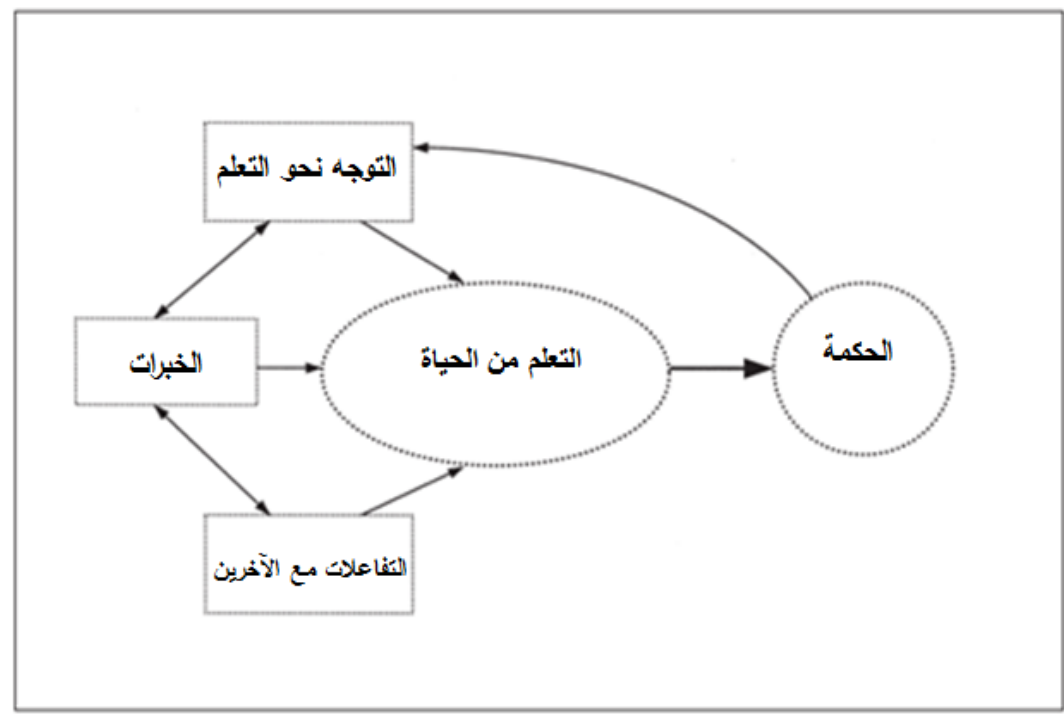

شكل (1) نموذج براون لتطوير الحكمة(GREENE, 2009, P293)

ومن خلا الثكل السابق ترى الباحثة أن تطور وتتميز المعرفة الذاتية بالأصالة الثخصية. ويصف

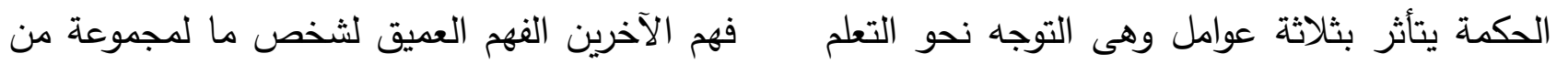
والخبرات والتفاعلات مع الآخرين، وهذه العوامل الأفراد فى سياقات مختلفة، والاهتمام بتعلم الآخرين يكتسبها الأفراد نتيجة التعلم من الحياة، وهذا لن (الانتباه، التعاطف)، والقدرة على النداجهم (مناهج

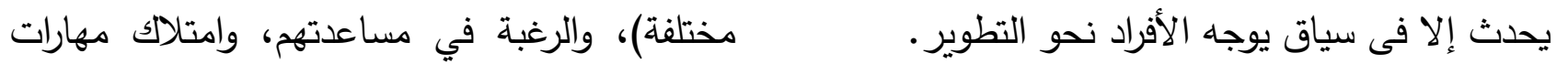

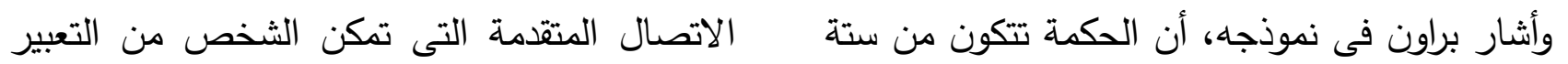

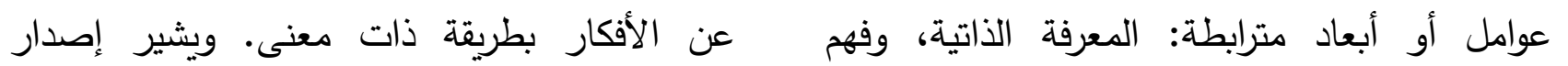

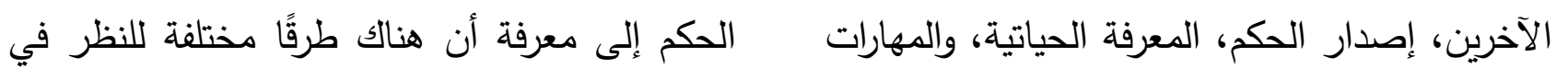

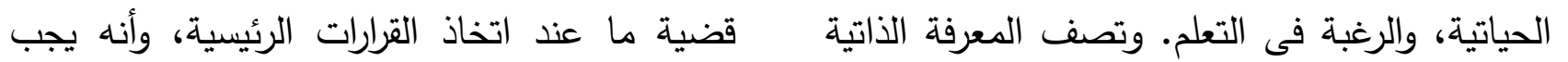
مدى إدرالك الشخص لاهتماماته ونقاط قوته وضعفه. الأخذ بعين الاعتبار مجموعة متتوعة من وجهات 
فى الحياة التى توصل إليها تحليل الفلاسفة والأنثربولوجيين، ثانيًا: أنها تتميز بالعمومية لأنها نتيجة لمستوى عال من الجريد الذى يسمح بالتتوع، وبهذا المعنى فإنها تجمع العالمية مع الخصوصية

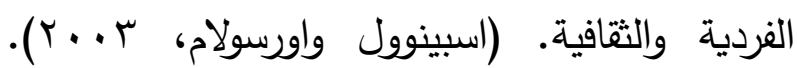
والحكمة تدرس على أنها سمة شخصية أو شكل من أشكال التفكير، وكذلك تعد مهارة لحل المشكلات حينما يواجه الفرد أمورًا صعبةً وغامضةًَ فى الحياة

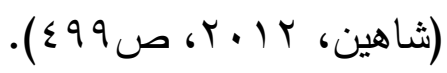
مما تقدم ترى الباحثة أن الحكمة تلعب دورًا هامًا فى اتخاذ الأفراد للقرارات الصحيحة عندما يتعرضون لأمور صعبة وغامضة، كما أنها تجعل المتعلمين يربطون ما تعلموه فى مواقف سابقة ويطبقونه فى المواقف الحالية، كما تمكن المتعلمين من فهم الأشياء المهمة فى حياتهم، والتعبير عن مشاعرهم بسهولة والتفكير العميق، كذلك التعبير والتحكم فى أفكارهم ومشاعرهم.

ولقياس الحكمة أعد Webster (2003, 2007) مقياسًا للحكمة تكون من خمسة أبعاد، وهم: الخبرة الحياتية الناقدة، والفكاهة، والانفتاح، والذكريات، وتتظيم

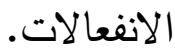
وتم تطوير مقياس ACL Wisdom Scale من إعداد Wink and Helson (1999) الشخصية في الحياة الاجتماعية اليومية والتى وصفها (1991) Achenbaum and Orwoll، والتى يمكن ملاحظتها من قبل الآخرين، وتأكيدها في
النظر ، والماضي، والسياق الحالي. وتشمل المعرفة

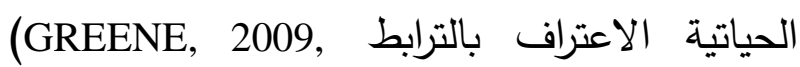
.PP292-293) مما تقدم ترى الباحثة أن أبعاد الحكمة تكمن فى الأبعاد الخمسة الآتية: التأمل Reflection ويعنى تذكر واستعادة الفرد للأحداث التى مر بها فى الماضى وربط تلك الأشياء بالمواقف الحالية وفهمها. والمزاج Mood ويعنى استخدام الفرد للفكاهة والضحك فى حياته للتغلب على المواقف الصعبة التى يمر بها. والتنظيم الأتى العاطفى Emotional self -regulation عن والتحكم فى أفكاره ومشاعره بسهولة وقدرته على فهم مشاعر الآخرين. والخبرة Experience وتعنى قدرة الفرد على التغلب على العديد من الحقائق المؤلمة واتخاذ القرارات الصائبة. والانفتاح العقلى Open-mindedness ويعنى قدرة الفرد على التفكير العميق حول العديد من القضايا وقدرته على مخالطة الأشخاص الذين تختلف وجهة نظرهم تمامًا عن

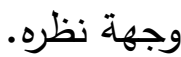
وأوضح Ferrari\& Potworowski (2008) أنه تكمن أهمية الحكمة أنها مصدر هام لحياة جيدة. كما توفر رؤى وتوجيهات للناس ليعيشوا حياة هادفة وسعيدة. وتعد الحكمة من المتغيرات المعرفية التى لها الدور المحورى فى تشكيل فاعلية الفرد، وهى من أكثر الحالات المستهدفة للنمو الإنسانى لسببين، أولاً: أنها مالها تمثل أعلى مستوى من المعرفة بالأهداف والوسائل 


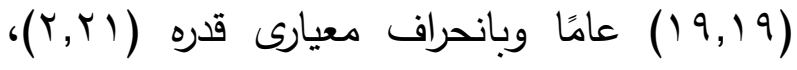
وكشفت نتائج هذه الدراسة عن وجود علاقة موجبة دالة إحصائية بين اليقظة الانفعالى والتنظيم الانفعالى.

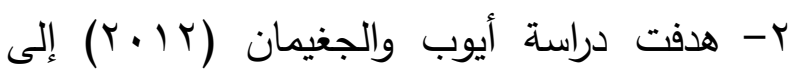
قياس أثر اكتساب الحكمة في تنمية التنكير الجدلي

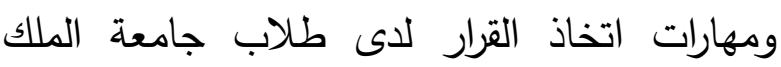
فيصل بالمملكة العربية السعودية، وطبقت هذه الدراسة على عينة تكونت من (عآ) طالباً وطالبة من الأقسام العلمية والأقسام الأدبية بالفرقتين الأولى العى والثانية بجامعة الملك فيصل بالمملكة العربية السعودية، وهم الطلاب الذين يمثلون الإرباعي

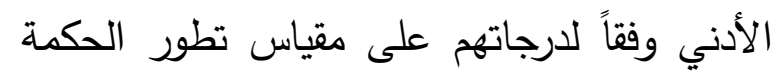

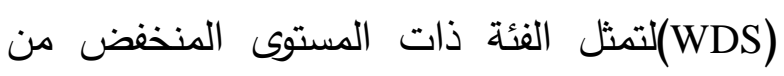
الحكمة، وكثفت نتائج هذه الدراسة عن وجود فروق دات دالة إحصائياً بين متوسطي درجات التطبيق القبلي والبعدي على بعدي التسامح مع التناقض، والمنظور

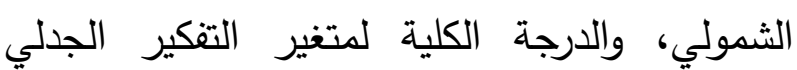
المنطقي. كما أظهرت النتائج وجود فروق دالة إحصائياً بين متوسطي درجات التطبيق التبلي

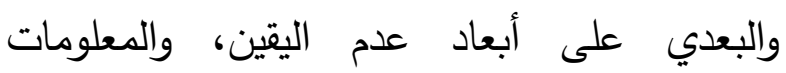
والأهداف، والنتائج المترتبة على اتخاذ القرار والدرجة الكلية لمتغير خصائص المهمة، وعلى أبعاد

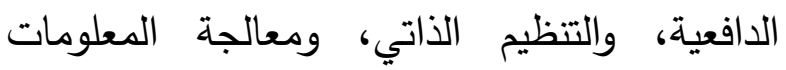

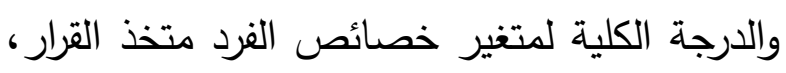

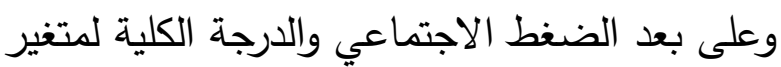

المعاملات مع البيئة (Wink \& Helson, 1999).

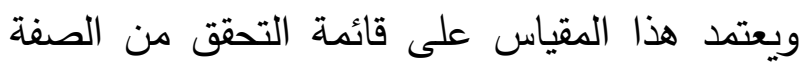
ويتكون من الأبعاد التالية: الوضوح، الإنصاف، هدئ،

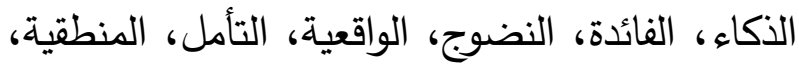
التسامح، الفهم، والحكمة. وقام Ardelt (2003, PP17-18) بتطوير مقياس/ تقييم ذاتي لقياس الحكمة. ويتكون المقياس من رن خمس استجابات من "موافق بشدة- غير موافق

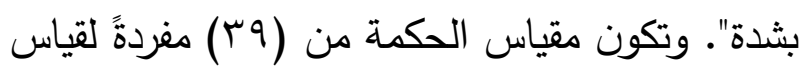

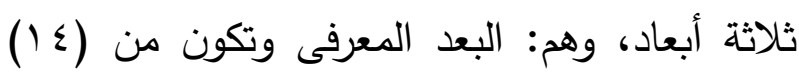
مفردةً، وبعد التأمل وتكون من (Y) (T) مفردةً، والبعد العاطفى وتكون من (T M ) مفردةً. مما سبق استفادت الباحثة من تلك المقاييس وصممت مقياسًا من إعدادها لقياس الحكمة، وتكون المقياس من (•ع) مفردةً تقيس خمسة أبعاد وهى (والمزاج والتأمل والتتظيم الذاتى العاطفى والخبرة والانفتاح العقلى). دراسات سابقة تناولت الحكمة:1- هدفت دراسة (2012) Hill\& Updegraff الكثف عن العلاقة بين اليقظة العقلية والتتظيم الانفعالى، وطبقت هذه الدراسة على عينة تكونت من

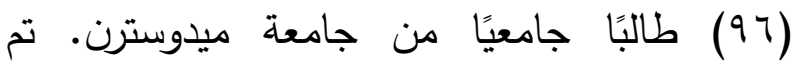

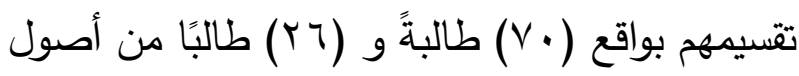
مختلفة (قوقازيين وأميركيين من أصل الصل أفريقى وآسيويين ومن ذوى الأصول الأسبانية) تتراوح

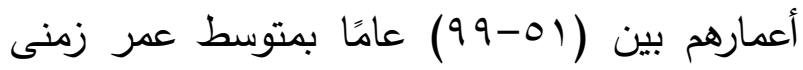


الانحدار المتعدد أن نموذج البيئة الثقافية والعمر

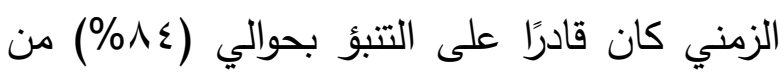

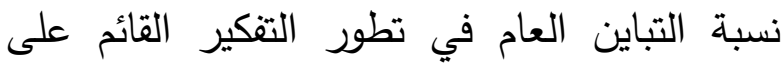

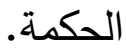

عoháriková; Špajdel; هدفت دراسة Cviková\& Jagla (2013) بين الحكمة والمرونة النفسية (وفقا لففهوم الصلابة لكوباسا) والأعراض النفسية، وطبقت هذه الدراسة

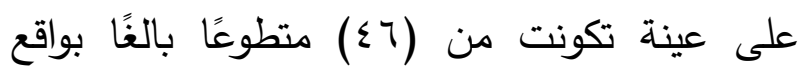

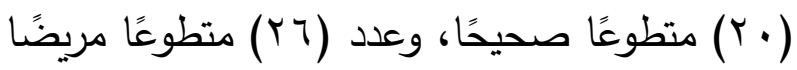

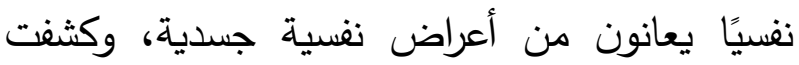
نتائج هذه الدراسة عن أن المرضى النفسيين سجلوا

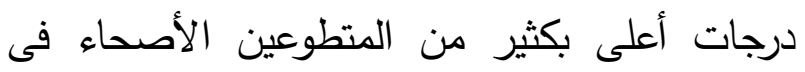
خمسة أبعاد للحكمة، ووجود علاقة سالبة دالة إحصائية بين الأبعاد الخمسة للحكمة وشدة ولهدة الأعراض النفسية باستثناء بُعد واحد وجدت علاقة لإعاد

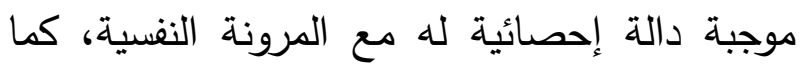
أثبت اثنان من هذه الأبعاد قيمتها التتبؤية السلبية تجاه الأعراض النفسية والقيمة التنبؤية الإيجابية نحو التهاد

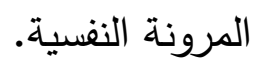

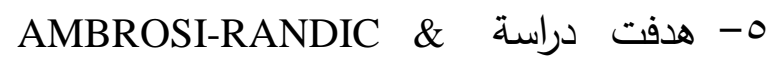
PLAVŠIC (2015) المستوى التعليمى للمشاركين فى تطوير الحكمة،

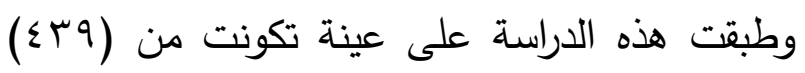

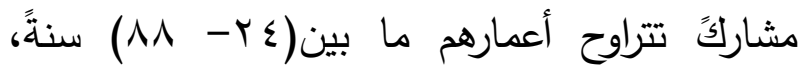
واستخدمت الباحثتان مقياس الحكمة المقيم ذاتيًا لـ لـ لـاعل
خصائص السياق. في حين أنه لم يكن هنالك تأثير

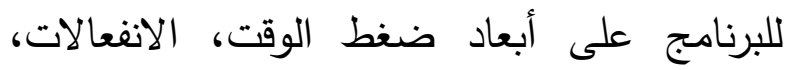

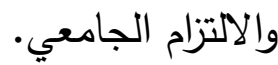

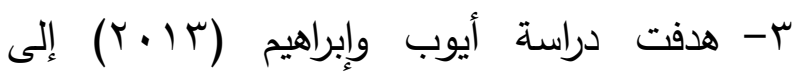
التعرف على مستويات تطور التنكير القائم على درابه الحكمة لدى طلاب الجامعة في دول الخليج العربي، كما يقاس بأسلوب التقرير الذاتي ووفقا لنموذج تطور Brown's Model of Wisdom الحكمة لبراون (Development (Brown, 2004a) على تأثيرات كل من الجنس والعمر والبيئات الثقافية على تطور الحكمة، وقدرة هذه المتغيرات على التتبؤ بتطور أبعاد الحكمة، وطبقت هذه الدراسة على عينة

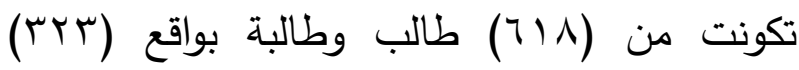
ذكور ، وعدد (90) إناث من طلاب الجامعات بكل من السعودية (YYT) وسلطنة عمان (Y.9) (Y.9)

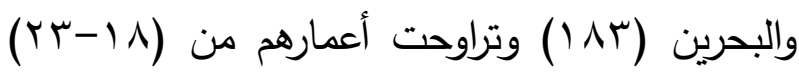
عامًا ، وكثفت نتائج هذه الدراسة عن وجود تطورًا متوسطًا في التفكير القائم على الحكمة لاى عيى عينة البحث وكانت هناك فروق دالة بين الطلاب والطالبات في متغيرات إدارة الانفعالات ومعرفة الحياة واصدار الأحكام لصالح الطلاب، في حين كانت الفروق دالة لصالح الإناث في بعد الاستعداد

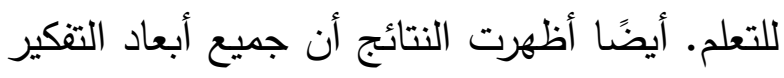

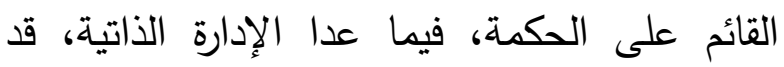
تطورت بتطور العمر ، وأن البيئة الثقافية لها تأثيرات الاداتهات التهات متباينة على تطور الحكمة. كما أظهرت نتائج تحليل 
Ardelt\& Jeste (2018) هدفت دراسة (إلى اختبار ما إذا كانت الحكمة ثلاثية الأبعاد كميـج من السمات الشخصية والمعرفية والتأملية والعاطفية، تتوسط العلاقة العكسية بين أحداث الحياة السلبية والرفاهية، وطبقت هذه الدراسة على عينة تكونت من

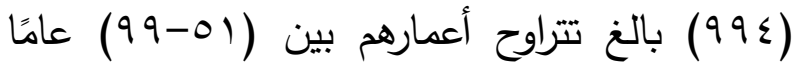
بمتوسط عمر زمنى (VV) عامًا، وكشفت نتائج هذه الدراسة عن وجود علاقة موجبة دالة إحصائية بين البعد التأملى للحكمة والرفاهية الشخصية، كذلك كثفت نتائج الدراسة عن وجود علاقة عكسية دالة إحصائية بين البعد أحداث الحياة السلبية والرفاهية

الشخصية.

ثانياً: اليقظة العقلية: -

اليقظة العقلية هى الوعى الذى ينشأ من خلال الانتباه المقصود أو المتعدد بطريقة منفتحة مع عدم

• (Shapiro \&Carlson, 2009) (إصدار أحكام وقد عرفت اليقظة العقلية بأنها القدرة على الإحضار المقصود للوعى بالخبرة فى اللحظة الحاضرة مع الاتجاه للانفتاح، وحب الاستطلاع (Baure,2011). كما عرفها الضبع ومحمود (rا. r) بأنها التركيز عن قصد فى اللحظة الراهنة دون إصدار أحكام تقييمية، أى يكون الفرد واعيًا بـ "هنا والآن" وأن يتقبل جميع خبرات الحياة الإيجابية والسلبية. وتتضمن الوعى والانتباه والتركيز على الأحداث الإيجابية أو السلبية فى اللحظات الحالية دون تفسيرها أو إصدار
والذى يتكون من خمسة (Webster, 2003, 2007) أبعاد: الخبرة، والتتظيم العاطفى، التذكر/ التأمل، الفكاهة والانفتاح، وكشفت نتائج هذه الدراسة عن عدم وجود فروق ذات دلالة إحصائية بين الأشخاص ذوى مستويات التعليم المختلفة (المدرسة الابتدائية والثانوية والكلية /الجامعة)، كذلك كشفت نتائج الدراسة عن وجود فروق ذات دلالة إحصائية بين المشاركين ذوى التعليم الابتدائى والتعليم الثانوى والتعليم الجامعى فى ثلاثة أبعاد من أبعاد الحكمة وهى بعد (التأمل والانفتاح والفكاهة) لصالح المشاركين ذوى التعليم الثانوى والتعليم الجامعى، فى حين لم توجد فروق دالة إحصائية بين المشاركين فى بعدى الخبرة والتظظيم العاطفى. 7MBROSI-RANDIC \& PLAVŠIC (2016) الطلاب الجامعيين لمعايير الحكمة المختلفة، وطبقت هذه الدراسة على عينة تكونت من (سا7) طالباً جامعياً بكليات العلوم الاجتماعية والإنسانية

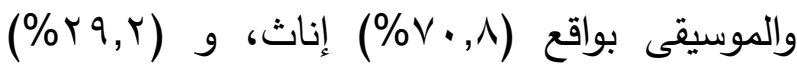
ذكور بمتوسط عمر زمنى (r-19) عامًا وبانحراف معيارى قدر (q r, ())، وكثفت نتائج هذه الدراسة عن أن الطلاب الجامعيين يوظفون المعايير المختلفة للحكمة فى المواقف الحياتية المختلفة، حيث أن معيار الحكمة الأكثر استخدامًا وتوظيفًا هو المعرفة الواقعية، تليها المعرفة الإجرائية. 
ومما تقدم ترى الباحثة أن اليقظة العقلية هى مدى قبولها للمواقف المختلفة واستبعاد الحكم الفورى مجموعة مؤشرات سلوكية تتعلق بمقدار قوة واستمراية عليها. الانتباه والملاحظة الآنية ومقدار التعامل الواعى ويوضح الثكل الآتى التفاعلات المتداخلة والمتبادلة والتأملى لدى الطالبة فى المواقف المختلفة وأخيراً بين مكونات اليقظة العقلية:-

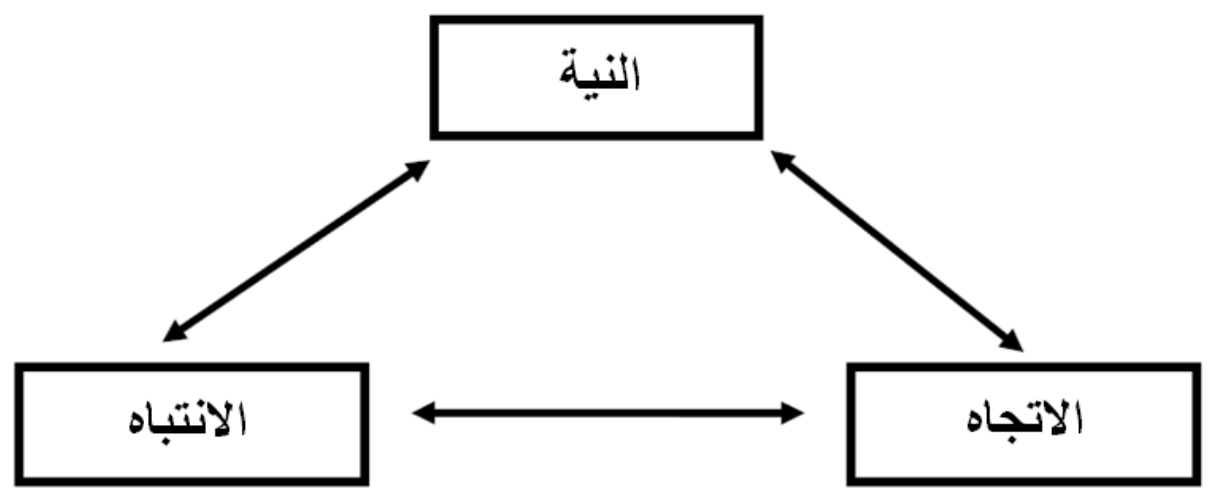

شكل (r) المكونات الثلاثة لليقظة العقلية

ا- المكون الأول: النية:-Intention وهى اليقظة العقلية مع الوعى، ولكن نوعية هذا الوعى المكون المركزى والأساسى لليقظة العقلية لما لها ليست موجهة بشكل صريح (Kabat-Zinn, 2003).

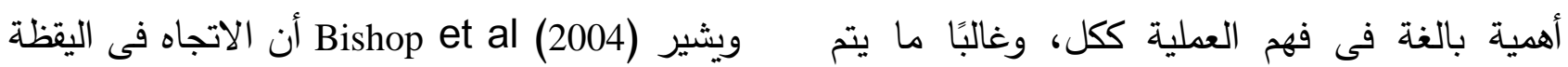
تجاهلها فى تعريفات أخرى (Bishop et al., 2004) • العقلية هو التوجه إلى الخبرة، والذى يتضمن r- Attention - - يتضمن الفضول وعدم السعى والقبول.

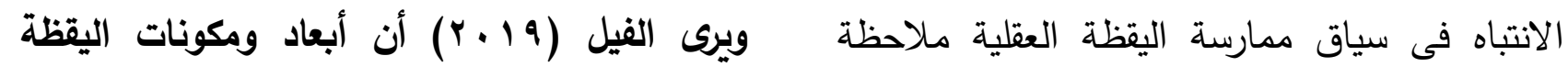
الفرد للعمليات لحظة بلحظة والخبرة الداخلية العقلية هى:والخارجية. ويمكن ملاحظة أهمية الانتباه فى العلاج - الانتباه والملاحظة الآنية:- يتمثل هذا البعد السلوكى المعرفى، الذى يقوم على القدرة على فى قدرة الفرد على الملاحظة الدقيقة المستمرة استدعاء (ملاحظة) السلوكيات الداخلية والخارجية. والانتباه المنظم والمقصود لكل ما يحدث فى اللحظة وجوهر اليقظة العقلية هو هذه الممارسة من الانتباه الآنية التى يُعايشها بكل تفاصيلها ومكوناتها وأبعادها (Shapiro, Sh., Carlson, L., Astin, J\& r - التعامل الواعى والتتأملى:- يتمثل هذا البعد فى Freedman, B, 2006) ب- المكون الثالث: الاتجاه: - Attitude الاتجاه قدرة الفرد فى على التعامل الواعى مع كل ما يحدث أمر ضرورى يؤثر على درجة انتباه الفرد وترتبط فى اللحظة الآنية وأحداثها الراهنة التى يُعايشها بكل 
مرتبطة بها، وأخيراً أن يصدر قرارات صحيحة بناءًا على أسس علمية.

دراسات سابقة تناولت اليقظة العقلية:-

1- Bدفت دراسة B. B (2013) إلى التعرف على التأثيرات الوسيطة المحتملة لليقظة العقلية والثفقة بالذات على سمة القلق، وسمات الثخصية السائدة فى العديد من بله الحالات النفسية، وطبقت هذه الدراسة على عينة

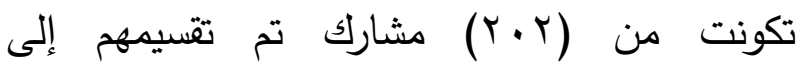
مجموعتين تكونت المجموعة الأولى من (1) (1) مشارك ممن تم استخدام معهم العلاج التأملى من لاعلى والمجموعة الثانية تكونت من ( 9 9) مشاركًا، وكثفت نتائج هذه الدراسة عن انخفاض كبير فى سمة القلق

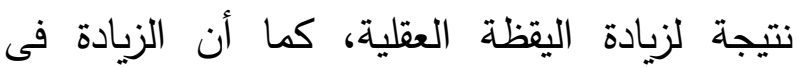

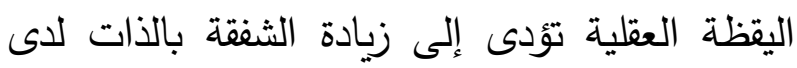
الفرد، فى حين لا تؤثر اليقظة العقلية فى تحديد العلاقة بين الثفقة بالذات والقلق، كذلك وجدت علاقة بين الثفقة بالذات واليقظة العقلية، كذلك كان بان لليقظة العقلية تأثير قوى فى خفض بل القلق كصفة

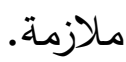

Quickel, E., Johnson, S\& كدفت دراسة. David, Z. (2014) اليقظة العقلية كسمة تستطيع تفسير التباين فى أداء

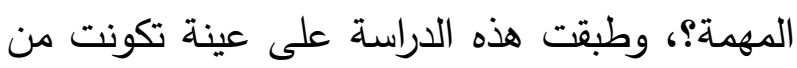

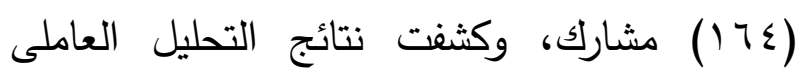
التوكيدى أن اليقظة العقلية كسمة لا ترتبط ولا تؤثر
تفاصيلها ومكوناتها وأبعادها، كذلك يتمثل فى قدرة الفرد على تأمل العلاقات بين مكونات الموقف الآنى أو اللحظة الآنية.

r- القبول واستبعاد الحكم:- يتمثل هذا البعد فى قدرة الفرد فى على قبول كل ما يحدث فى الموقف الآنى أو اللحظة الآنية والانصياع له له بدون وجود

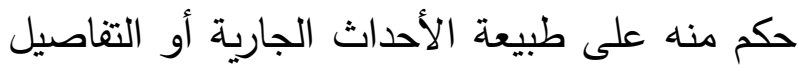
المكونة لما يحدث. وسوف تعتدد الباحثة على هذه

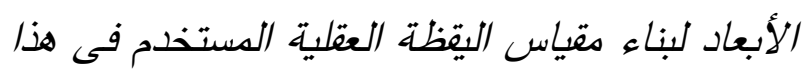

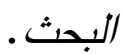

ولدمج اليقظة العقلية فى عملنا وحياتتا الثخصية نحتاج إلى البداهة وفهم الممارسة الفكرية. لذلك نحن بحاجة إلى معرفة كيفية ممارسة اليقظة العقلية فى الى لئه الواقع من أجل الحصول على فوائدها، ويتم استخدام ممارسات اليقظة العقلية لتعزيز علاقاتنا الشخصية

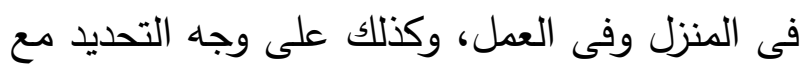
الأطفال والمراهقين (Y) (Siegel, R. 2014).

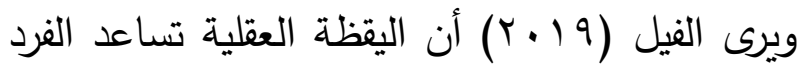
على أن يكون منظمًا فى خطوات تفكيره لحل المشكلات، وأن يرى الموضوعات من وجهات نظر

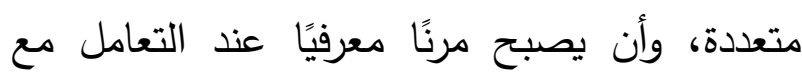
المواقف المختلفة، وأن يكون منفتحًا لتقبل وجهات مدات النظر الأخرى، كذلك تساعده على أن يكون فعالاً

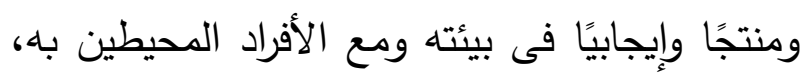
و أن يتقبل التغيير ويسعى إلى إحداثه، وأن يتأمل الموضوعات والمواقف المختلفة قبل إصدار أحكام 
النسبى لمتغيرات النوع، ومستوى فعالية الذات، والدعم الاجتماعى المدرك من الأصدقاء والعائلة، واليقظة العقلية على التنبؤ بمجالات التوافق الجامعى (الأكاديمى، والاجتماعى، والشخصى أو الوجدانى، والتعلق المؤسسى)، وطبقت هذه الدراسة على عينة تكونت من (1 (1) طالب جامعى من طلاب الفرقة

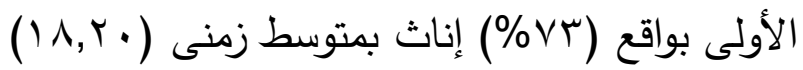
عامًا وبانحراف معيارى قدره (V9, • · )، وكشفت نتائج هذه الدراسة أن اليقظة العقلية تمكن من التنبؤ بالتوافق الجامعى حتى فى حالة عزل أثر فعالية الذات والدعم الاجتماعى المدرك من الأصدقاء والعائلة.

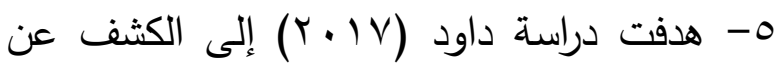
وجود فروق فى اليقظة العقلية والتعاطف الذاتى للى مرضى الاكتئاب الرئيس مقارنةً بنظرائهم غير المرضى، وعن علاقة اليقظة العقلية والتعاطف الذاتى بالاكتئاب والخلل الوظيفى، كما هدفت إلى الكشف عن القدرة التنبؤية لليقظة العقلية والتعاطف الذاتى بالاكتئاب والخلل الوظيفى، وطبقت هذه الدراسة على عينة تكونت من (NV) فردًا بواقع (r) ذكرًا و (OV) من المشخصين بالاضطراب الاكتئابى الرئيس، ممن يراجعون مراكز الصحة النفسية، العامة والخاصة فى مدينة عمان بالإضافة

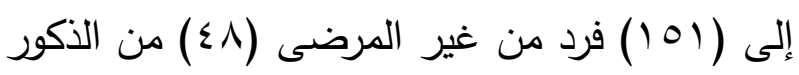
وعدد (r • (1) إناث لأغراض المقارنة، وكشفت نتائج هذه الدراسة عن وجود فروق دالة بين مرضى
فى التباين فى أداء المهمة فى المهام التى تتطلب انتباهًا مركزًا، كما أشارت النتائج إلى أن مقاييس اليقظة العقلية لا تشتمل على قياس الانتباه؛ وذلك لأن الأفراد الذين يسجلون درجات مرتفعة فى مقاييس اليقظة العقلية لا يؤدون بشكل أفضل فى المهام التى تتطلب انتباهًا مركزًا عن أولئك الذين يسجلون درجات منخفضة فى مقاييس اليقظة العقلية. Wang, Y ., Xu, W \& Luo, F. ب- هدفت دراسة (2016)إلى تقييم دور الصلابة الوجدانية كوسيط بين اليقظة العقلية والتظيم الوجدانى، وطبقت هذه الدراسة على عينة تكونت من (IYI) طالب من طلاب الجامعة بمتوسط عمر زمنى (r) عامًا وبانحراف معيارى قدره عامين بواقع ( I I ) طالب، وعدد (Y ) طالبة وعدد (乏) طلاب تم استبعادهم، وكشفت نتائج هذه الدراسة عن أن الصلابة الوجدانية تتوسط العلاقة بين اليقظة العقلية والتظيم الوجدانى، كما أن القدرة على توليد الوجدانات الموجبة تتوسط العلاقة بين اليقظة العقلية وكل من الوجدانات الموجبة والسالبة فى حين أن القدرة على التعافى من الوجدانات السالبة تتوسط العلاقة بين اليقظة العقلية والوجدانات السالبة، وتثير هذه النتائج إلى أن اليقظة العقلية قد تلعب دورًا فى تنظيم الوجدانات الموجبة والسالبة من خلال جانبين مختلفين من الصلابة الوجدانية.

צettler, J., Carsley, D., Joly, هدفت دراسة M\& Heath, N. (2017) 
العقلية تبعًا لمتغيرى الجنس (ذكر ، أنثى) والتخصص (علمى، إنسانى)، وطبقت هذه الدراسة على عينة تكونت من ( . . (1) طالب وطالبة، وكشفت نتائج هذه الدراسة عن أن طلبة الجامعة لديهم مستوى جيد من اليقظة العقلية، وعدم وجود فروق فى اليقظة العقلية تبعًا لمتغيرى الجنس (ذكر، أنثى)، والتخصص (علمى، إنسانى) . (على)

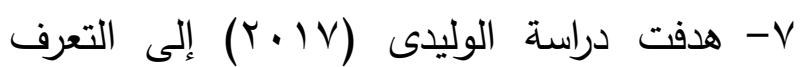
على مستوى اليقظة العقلية لدى طلاب جامعة الملك خالد، وكذلك الكشف عن الفروق بينهما فى مستوى اليقظة العقلية، كما هدفت إلى معرفة العلاقة بين اليقظة العقلية والسعادة النفسية، وكذلك هدفت إلى التنبؤ بالسعادة النفسية من خلال اليقظة العقلية، وطبقت هذه الدراسة على عينة تكونت من (YVO) طالب وطالبة حيث بلغ عدد الطلاب (I I ) طالب،

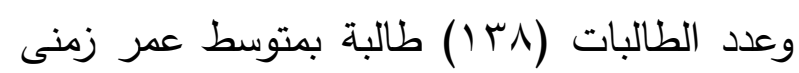

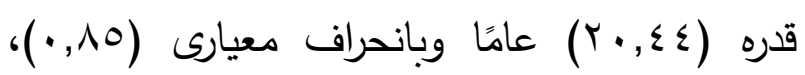
وكشفت نتائج هذه الدراسة عن وجود مستوى متوسط من اليقظة العقلية لدى طلاب الجامعة، ووجود علاقة ارتباطية دالة إحصائيًا بين اليقظة العقلية والسعادة النفسية فى بعد واحد فقط من أبعاد اليقظة العقلية وهو الاستقلال الذاتى، فى حين لم تكن العلاقة دالة إحصائيًا فى الدرجة الكلية وباقية الأبعاد، كما وجدت فروق دالة إحصائيًا بين الجنسين فى اليقظة العقلية وكانت الفروق لصالح الطالبات، كما خلصت النتائج إلى إمكانية التنبؤ بالسعادة
الاكتئاب الرئيس ونظرائهم من غير المرضى فى اليقظة العقلية والتعاطف الذاتى، وكانت الفروق لصالح مجموعة المقارنة. كما كشفت عن وجود ارتباط سلبى بين الاكتئاب واليقظة العقلية، وبين الاكتئاب والتعاطف الذاتى، كما بينت أن الارتباط بين الخلل الوظيفى واليقظة العقلية وبين الخلل الوظيفى والتعاطف الذاتى كان سالبًا. كما بين تحليل الانحدار الخطى البسيط قدرة اليقظة العقلية والتعاطف الذاتى على التنبؤ بالاكتئاب والخلل الوظيفى، وعند استخدام تحليل الانحدار الخطى المتعدد للتنبؤ بالاكتئاب والخلل الوظيفى من خلال اليقظة العقلية والتعاطف الذاتى، وأظهرت النتائج قدرة التعاطف الذاتى على التتبؤ بالاكتئاب والخلل الوظيفى، وقدرة اليقظة العقلية على التنبؤ بالخلل الوظيفى، بينما لم تتمكن اليقظة العقلية من التتبؤ بالاكتئاب، ووجود قدرة لدى بعدين من أبعاد اليقظة العقلية وهما: التصرف بوعى فى اللحظة الحاضرة، وعدم التفاعل مع الخبرات الداخلية، على التنبؤ بالاكتئاب والخلل الوظيفى، كما أظهرت النتائج قدرة بعدين من أبعاد التعاطف الذاتى على التنبؤ بالاكتئاب وهما: اللطف بالذات، والإفراط فى تحديد هوية الذات، كذلك أظهرت النتائج قدرة الحكم الذاتى واليقظة العقلية على التنبؤ بالخلل الوظيفى.

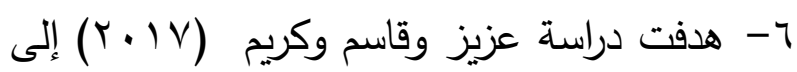
التعرف على مستوى اليقظة العقلية لدى طلبة الجامعة، والكشف عن دلالة الفروق فى اليقظة 
الحياة لديه، ويفترض مفهوم فعالية الحياة وجود بعض الخصائص والسمات الشخصية التى تعمل كعوامل كافية وفعالة لتحقيق الأهداف والرغبات فى (Verešová, M., Čerešník, M \& Malá, D, الحياة.

وظهرت العديد من المرادفات لمهارات فعالية الحياة، حيث يُشير مصطلح Life إلى الحياة الشخصية أو الحياة الاجتماعية للفرد فى حين يُشير مصطلح Effectiveness

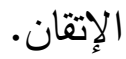
وتُشير مهارات فعالية الحياة إلى السلوك، والإدراك، والعواطف التى تميز الفرد فى المواقف المختلفة، وهذه المهارات قابلة للتحسين والتعلم والتتمية؛ لأنها تختلف عن سمات الشخصية التى يكون من الصعب التعامل معها تجربيًاًا. (Neill, J, 2008B) وتمثل فعالية الحياة مجموعة مهارات متعددة الأبعاد وديناميكية وعامة يمكن تتميتها نظريًا وعمليًا، وتتمثل فعالية الحياة فى الفعالية فى الحياة العملية والحياة

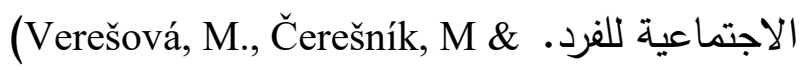
Malá, D, 2013) اعتقاد الفرد بأنه يمتلك الكفاءات النفسية والسلوكية اللازمة التى تمكنه من أن يكون فعالاً فى أى لى لى موقف. (Bloemhoff, H, 2016) كما أن فعالية الحياة هى بعض المهارات الشخصية والاجتماعية التى تمثل عواملاً هامةً فى مدى فعالية الشخص وقدرته على تحقيق رغباته وطموحاته فى
النفسية من خلال اليقظة العقلية وذلك لدى الطالبات فقط. ثالثاً: مهارات فعالية الحياة:-تمثل مهارات فعالية الحياة إمكانيات الشخص لكى يعيش حياته بفعالية وهدف. حيث تؤثر القدرات والمهارات الشخصية التى يمتلكها الفرد على فعالية الحياة لدياه، ويفترض مفهوم فعالية الحياة وجود بعض الخصائص والسمات الشخصية التي تعمل كعوامل كافية وفعالة لتحقيق الأهداف والرغبات فى (Verešová, M., Čerešník, M \& Malá, D, .الحياة (2013, p842) وظهرت العديد من المرادفات لمهارات فعالية الحياة حيث يُشير مصطلح Life إلى الحياة الثخصية أو الحياة الاجتماعية للفرد فى حين يُشير مصطلح Effectiveness إلى الفعالية أو أو الكفاءة أو المهارة أو الإتقان، ويوضح الجدول الآتى مردافات مصطلح فعالية الحياة. وينظر إلى فعالية الحياة على أنها الطريقة التى يفكر، ويعمل ويستجيب بها الفرد فى مجموعة متتوعة من المواقف. وتشمل أبعاد مهارات فعالية الحياة إدارة الوقت، والكفاءة الاجتماعية، ودافعية الإجاز، والمرونة الفكرية، وقيادة المهمة، والضبط العاطفى والمبادرة الفعالة، وترتبط فعالية الحياة ارتباطًا وثيقًا بالنجاح فى الحياة. (Neill, J, 2008) كما تمثل مهارات فعالية الحياة إمكانيات الشخص لكى يعيش حياته بفعالية وهدف. حيث تؤثر القدرات والمهارات الشخصية التى يمتلكها الفرد على فعالية 
الوقت للتخطيط لمهنة أفضل، والاستعداد للمستقبل، وقراءة ومعرفة المزيد، ومتابعة التطورات والتحسينات فى التكنولوجيا، وتوفير المزيد من الوقت لأفراد العائلة والمعارف، والترفيه، والتفكير، وخلق أفكار جديدة وبدء مشاريع جديدة. وقد ذكر كوفى (2004) Covey أن هناك سبعة أمور يجب على الشخص أن يعطيها أولويات من أجل إدارة الوقت بشكل جيد، وهذه الأمور هى: تحسين التواصل مع الآخرين، وإعداد الأنشطة بشكل أكثر فعالية، وتحسين عملية الإدارة والتخطيط للواجبات، ورعاية المصالح الشخصية، واغتنام الفرص الجديدة، وتحسين المهارات الشخصية والمعلومات، والاعتراف بقوة الآخرين.

CYRIL (2015, وبالنسبة لأهمية إدارة الوقت أشار أن الطلاب يتمتعون بشكل عام بحياة مزدحمة ومجهدة للغاية؛ لأنهم يحضرون الدروس، ويستكملون المهام الدراسية ويدرسون للامتحانات. وبالإضافة إلى ذلك، فإن لديهم روتين فى حياتهم وأنماط حياتهم اليومية الضرورية لتحقيق التوازن بين الأنشطة الأكاديمية والإضافية على المناهج الدراسية. ومع ذلك، فإن إيجاد الوقت للقيام بكل شىء في وقت واحد يمكن أن يكون تحديًا. ويعد ذلك هو الوقت المناسب لتطبيق مهارات إدارة الوقت الجيد. وهى مهارة يحتاج الطلاب إلى تعلمها. ويجب عليهم اتخاذ المداخل اللازمة وتطبيق هذه الاستراتيجيات من أجل أن تكون فعالة وأكثر إنتاجية. وتوفر هذه المهارات
الحياة، كما أنها قدرة الفرد على التكيف والبقاء والنمو. (Betty, P, 2015) 1 إدارة الوقت:- Time Management تعد إدارة الوقت قضية جديرة بالاهتمام؛ نظرًا لكونها عاملاً أساسيًا فى أى نجاح على جميع مستويات الحياة، ولذلك يرتبط مصطلح إدارة الوقت بشدة بالعمل الإدارى. وعلى الرغم من أهميته، فإنه ليس من السهل أبدا إدارة الوقت بشكل فردى، فالحاجة إلى مؤهلات محددة بجانب العديد من المهارات الشخصية تعد ضرورة. بالإضافة إلى استغلال الموارد المتاحة من أجل تلبية احتياجات المجتمع والاحتياجات الفردية فى نفس الوقت، والقدرة على

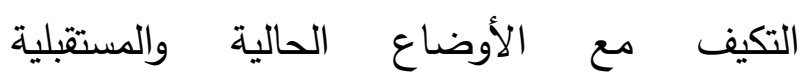
.(Alghamdi, 2008, p49) وأشار MacCann and et al (2012) أن إدارة الوقت قد تتأثر بالمعرفة (مثل تحديد الأهداف) والسياق (2015, مثل دور البيئة الدراسية). كما عرف ل) Akcoltekin P2242) تأتى فيها الأحداث من الماضى وتتبع بعضها البعض في المستقبل. ويضيف Çelik (2002) أن الوقت هو الفترة الزمنية الضرورية للقيام ببعض ولية الوظائف أو العمل. وعرف Ugur (2000, p18 إدارة الوقت بأنها الجهد فى استخدام الوقت بكفاءة كمورد أساسى للوصول Sayan إلى الأهداف والغايات. كما عرّف سايان (2005)إدارة الوقت بأنها الفرصة لتوفير مزيد من الن 
الاجتماعية هى القدرة على دمج المشاعر والتفكير،

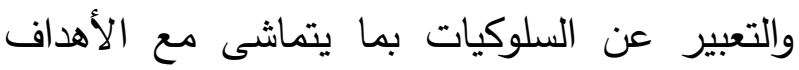

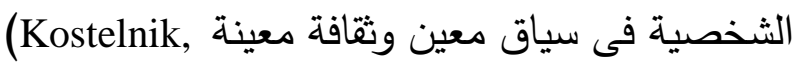

.Gregory, 2005) Whiren, Soderman, \& كما أنها بنية متعددة الأبعاد. وتشمل الكفاءة الاجتماعية الأبعاد الاجتماعية والمعرفية والعاطفية والثخصية التى تتفاعل مع بعضها البعض البه .(Lianos, 2015)

وتتكون الكفاءة الاجتماعية من مكونات رئيسية هى التعاون والكياسة والصراحة والديناميكية والهيمنة والاندفاع والطموح والصداقة ومهارات التواصل بين

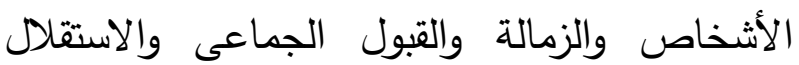
والاهتمام ومهارات الحزم والثقة والتحكم العاطفى والتحكم فى الاندفاعات والانبساط (Lianos, 2015).

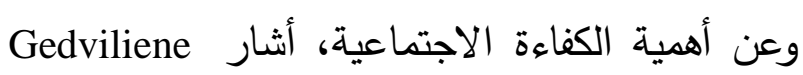

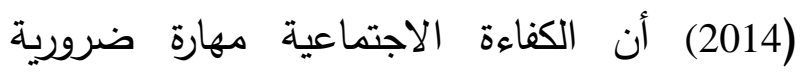
وحيوية للأفراد الذين يعانون من الصعوبات، وللحفاظ على العلاقات الاجتماعية بشكل إيجابى، وللمشاركة

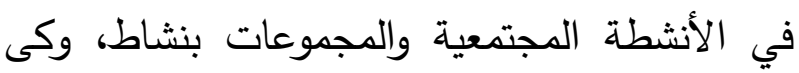
يكونوا مستقلين ونشطين. كما أن الكفاءة الاجتماعية

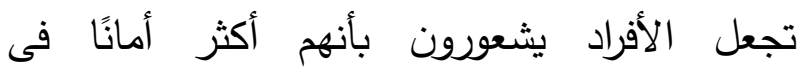

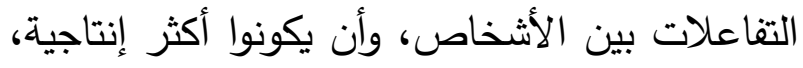

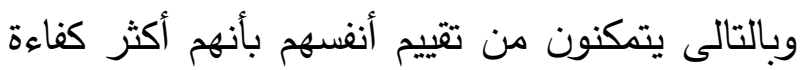
فى العلاقات الشخصية (Erözkan, 2013).
للطلاب القدرة على التخطيط المسبق وتحديد أولويات المهام والأحداث القادمة. وهذا هو عامل مهم فى الحفاظ على تتظيم الطلاب وتجنب التسويف، ويؤدي في النهاية إلى النجاح الأكاديمى. ويمكن أن تكون مفيدة جدًا في جدول الطالب المحموم. وتضمن إدارة الوقت الجيد أن الطلاب يكونوا على استعداد جيد، وتنظيم وتركيز على إدارة

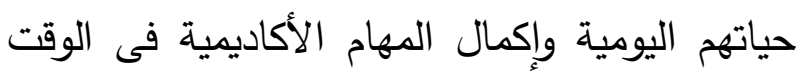
المحدد. ويمكن أن يؤدى ذلك إلى تحسين النجاح، ومع ذلك، فهذه هى المهارة التي يجب على الطلاب تعلهها وممارستها. ويجب على الطلاب تغيير عاداتهم من أجل امتلالك مهارات إدارة الوقت الجيد. ويمكن أن يحدث هذا فقط إذا قام الطلاب بالخطوات الأولى فى تحديد مشاكلهم. وتتبع مهارات إدارة

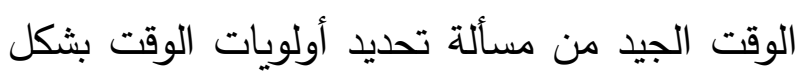

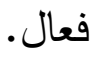

Social Competence - ب الكفاءة الاجتماعية تعد الكفاءة الاجتماعية نتيجة للخبرات السابقة،

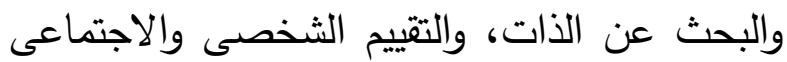
.(Coleman, 2003; Ten-Dam, \& Volman, 2007) Sarıçam, Akın, Akın\& Çardak (2013) وعرفت الكفاءة الاجتماعية بأنها قدرة الأفراد على استخدام

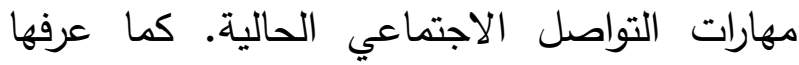
Magelinskaite, Kepalaite\& Legkauskas (2014) بأنها استخدام الأفراد لمهاراتهم الاجتماعية بكفاءة خلال التفاعل أو التواصل الاجتماعى. والكفاءة 
وتعد هذه القدرة الأوساط الأكاديمية هى المفتاح، مما يسمح للأطفال بإتقان المعلومات الجديدة بفعالية، وتعديل أنماط سلوكهم وفقًا لأفكارهم الناضجة وفهمهم للعالم من حولهم؛ وينطبق الثىء نغسه على العمل والإعدادات الاجتماعية في مرحلة المرهقة

.(Dajani\& Uddin, 2015)

وعرف McNulty et al (2010) المرونة العقلية بأنها قدرة الفرد على تغيير وجهته الذهنية تجاه المثيرات الجديدة والطارئة عند مواجهته لموقف أو مشكلة ما، وانتاجه العديد من الأفكار المتتوعة فى أقل وقت ممكن سعيًا للوصل إلى حل تلك المشكلة. وتعد المرونة العقلية واحدة من أكثر الوظائف التنفيذية المعرفية الذكية للبشرية، حيث تمثل القدرة على تغيير وتحديث المخرجات الإدراكية والسلوكية بشكل مستمر استجابة للتغيرات البيئية. فهى تسمح للشخص بالتفاعل وأن يكون فعالاً مع المحيط (Armbruster, Ueltzhöffer, Basten, \& Fiebach,

كما أن المرونة العقلية هي وظيفة تتفيذية معقدة تعتمد على مختلف الوظائف المعرفية الأخرى للتفيذ السليم. وبشكل أكثر تحديدًا، فإن الكشف عن الانتباه والذاكرة العاملة، والتثبيط، والتبديل، كلها أمور تلعب

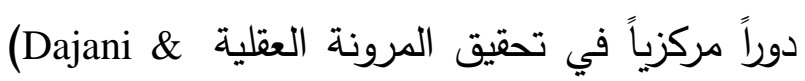
.Uddin, 2015)
Achievement Motivation - : ب- دافعية الإنجاز تعد دافعية للانجاز من المفاهيم النفسية التي أثارت جدلًا ونقاشًا بين علماء النفس وحظيت باهتمامهم إذ لـ لهي تصدت لها البحوث والدراسات لوصفها وتفسيرها واخذ كل باحث يعرفها من إطار عمله ومن إطار النظرية التي يتبناها، ويشير التطور التاريخي لمفهوم دافعية الانجاز إن استخدام مصطلح الدافع للانجاز في علم النفس يرجع من الناحية التاريخية إلى" الفرد ادلر Adler " الذي أشار إلى أن الحاجة للانجاز هي دافع تعويض مستمد من خبرات الطفولة (بنى

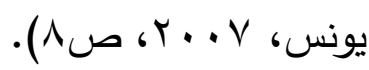
عرف Santrok (2003, 103) أن الدافعية للإنجاز هى الرغبة في تحقيق شيء ما لتحقيق معيار للنجاح، ولجعل العمل يهدف إلى تحقيق النجاح. كذلك أشار Osvaldo (2011, P82) أن الدافعية للإنجاز لها تأثير إيجابي ودال إحصائيًا على الأداء. وتكمن أهمية دافعية الإنجاز فى كونها تتمي العديد من الخصائص لاى الفرد ومنها: السعي نحو الإتقان والتميز، والقدرة على تحديد الهدف، والقدرة على استكشاف البيئة والقدرة على تحمل المسؤولية والقدرة على التعامل مع الذات، والقدرة على تعديل المسار ، (Petri\& Govern, والقدرة على التخطيط الجيد 2004)

ع - المرونة العقلية:- Intellectual Flexibility والمرونة العقلية أمر حاسم للتعلم، والتكيف مع التغيرات أو العقبات غير المتوقعة في بيئة الفرد. 
Active Initiative - - - المبادرة النشطة: تتمثل فى قدرة الفرد على القيام بنشاط وباستقلالية

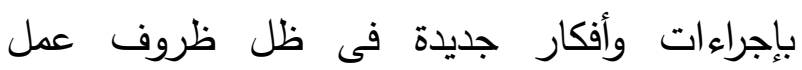
مختلفة. كما تتمثل فى تطوع الفرد للقيام ببعض طرول الأعمال والمشاركة فى المواقف المختلفة، وتعزز المبادرة النشطة من أداء الفرد فى المواقف المختلفة، كما أنها تُكننه من السيطرة على حياته الشخصية ادلية

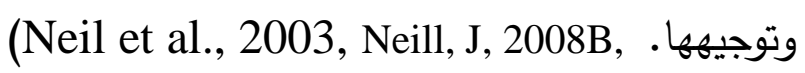

\section{-}

أشار McPheat (2010 أن الثقة هى الاعتقاد بأن

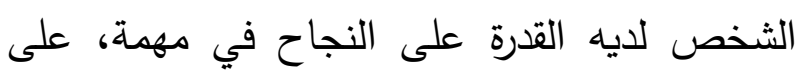
أساس القدرة /أو غياب هذه القدرة على القيام بهذه

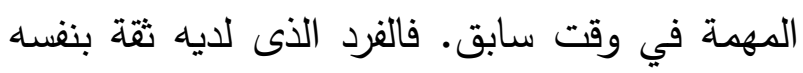
يكون قادرًا على التطوير ، والحد من المواقف السلبية،

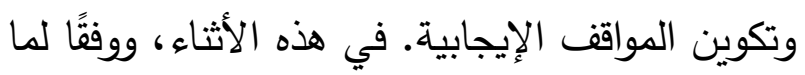
ذكره Lautser (in Hendriana, 2012, 93) العديد من الخصائص لتقييم ثقة الأفراد، مثل:

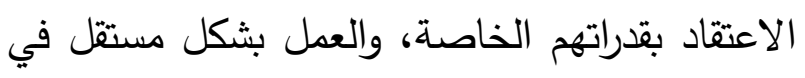

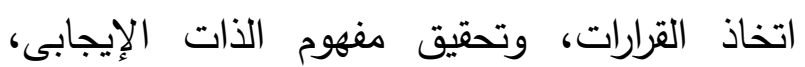
والثجاعة فى التعبير عن الآراء.

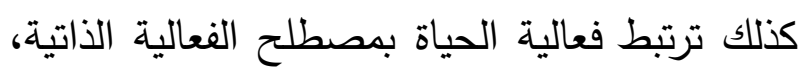

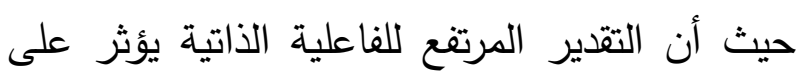
خلق الفرد لاتجاهات إيجابية، كما يُكنه من تفسير المهام الصعبة باعتبارها تحديات ويؤثر على جودة

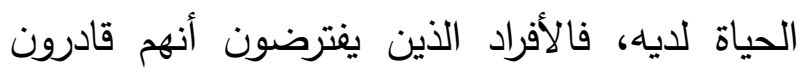
على السيطرة على الأحداث هم قادرون على التعامل
ه- قيادة المهمة:- Task Leadership يشارك ق قادة المدارس في المهام والممارسات (Halverson, 2005, الأساسية لوضع شروط التعلم فاركات 2006; Spillane, 2005) كيف يجمع القادة بين تفاعلات المدرسة والقيادة والمتابعة (Spillane, 2005). Griffin (1995) and Halverson (2003, وأوضح (2006 أن قيادة المهمة لها فوائد متعددة، تتضمن الآثار الإيجابية في التربية، والثقافة المدرسية، والجودة التعليمية. צ- التحكم فى الوجدانات: - Emotional Control يثير التحكم فى الوجدانات إلى نمط السلوك للفرد

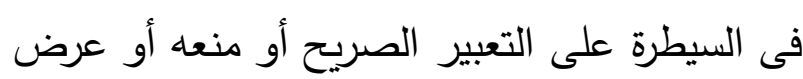

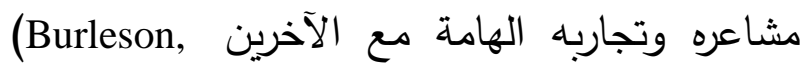
$.2003)$

ويختلف الأشخاص في درجة تحكمه الوجدانى

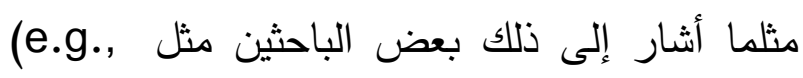
.Pennebaker, 1989; Watson et al., 1991) وأوضح Pennebaker (1989, 2002) أن أنماط الأشخاص في التحكم أو عدم التحكم في تعبيرهم الوجدانى قد يكون له تأثيرات مختلفة على وظائفهر النفية خلال الأوقات العصيبة أو الصادمة. وأوضح Cole, Martin, \& Dennis (2004) أن النئ التحكم الضعيف فى الوجدانات يلعب دورًا مهمًا فى تتمية وتطوير المشكلات الوجدانية والسلوكية. 
كل جانب من جوانب البرنامج، وكذلك وجود فرق ذات دلالة إحصائية بين مهارات فعالية الحياة لدى الذكور الذين شاركوا فى برنامجين للتعلم خارج الصف مقارنةً مع برنامج واحد فقط.

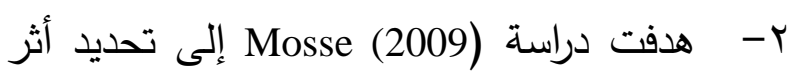
المشاركة فى برنامج العلاج الترفيهى القائم على التى

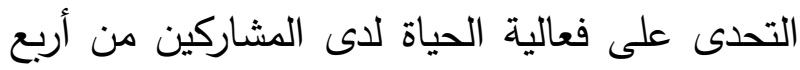
مجموعات جنسية مختلفة، وطبقت هذه الدراسة على عينة مكونة من (ro) طالبًا من أربعة بلدان

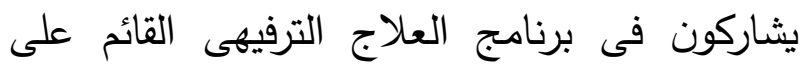
التحدى لمدة شهرين والذى أقيم فى معسكر تدريب للقوة الأيرلندية لحفظ السلام فى ريف أيرلندا،

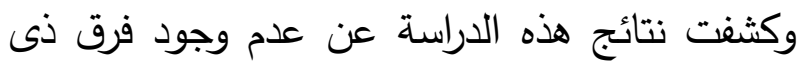
دلالة إحصائية بين الاختبار القبلى والاختبار البعدى

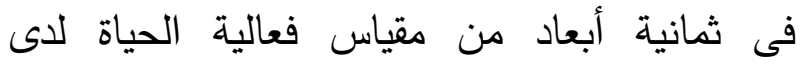
المشاركين، ووجود فروق ذات دلالة إحصائية بين

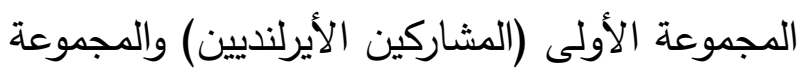
الثالثة (المشاركين الفلسطينيين) فى بعد المرونة المينة الفكرية، وكذلك وجود فرق ذى دلالة إحصائية بين المجموعة الثالثة (المشاركين الفلسطينيين) والمجموعة الرابعة (المشاركون فى بلجيكا) فى بعد

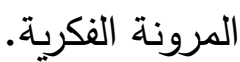
r- هدفت دراسة (2009) Merrell إلى قياس أثر برنامج قيادة الإلهام على فعالية الحياة ومركز التحكم على مجموعة من طلاب الصف السادس فى مدرسة شولتز المتوسطة، وطبقت هذه الدراسة على عينة
بشكل أفضل مع حالتهم الوجدانية الخاصة، وأيضًا قادرون على التعامل بشكل أفضل مع مواقف الحياة

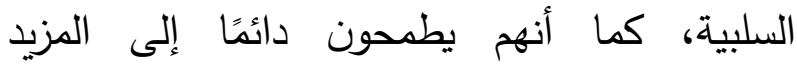
ويقاومون الفشل. \&erešová, M., Čerešník, M \& Malá, D, 2013) وعن الفروق فى مهارات فعالية الحياة وفقًا لبعض Betty, P المتغيرات الديموجرافية كثفت نتائج دراسة (2015) عن وجود فروق دالة إحصائيًا فى مهارات فعالية الحياة لدى الطلاب المعلمين تبعًا للمنطقة السكنية ونوع المؤسسة التعليمية، وعدم وجود فروق دالة إحصائية فى فعالية الحياة لدى الطلاب المعلمين تبعًا للنوع، كما كثفت نتائج دراسة عن Cosmas, G., Seok, C\& Hashmi, S. (2016) وجود فروق ذات دلالة إحصائية بين الذكور والإناث فى مهارات فعالية الحياة وثلاثة من مكوناتها (الدافع للإنجاز ، المرونة الفكرية، والقيادة) لصالح الإناث. دراسات سابقة تناولت مهارات فعالية الحياة:ו- - هدفت دراسة (2004) McCleod\& Craig تقييم فعالية التعلم الخبراتى وبرنامج التعلم خارج الصف فى الددرسة على مهارات فعالية الحياة للدارسين الذكور بالمرحلة المتوسطة، وطبقت هذه الدراسة على عينة مكونة من (؟ • () طالب من إحدى مدارس الجامعات الواقعة فى جميع أنحاء الضواحى الجنوبية الشرقية بمدينة ملبورن وبمتوسط عمر زمنى (؟ () عامًا، وكثفت نتائج هذه الدراسة عن أن مهارات فعالية الحياة لاى الذكور زادت بعد الاعد 


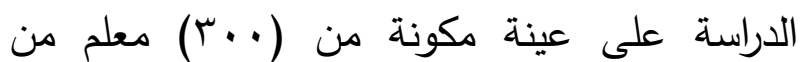
الطلاب المعلمين تم اختيارهم من مؤسسة تعليم المعلمين فى مناطق إرناكولام وكوتايم وإيدوكى فى ملى موني ولاية كيرالا، وكثفت نتائج هذه الدراسة عن وجود فروق دالة إحصائية فى فعالية الحياة لدى الطلاب المعلمين تبعًا لـ (المنطقة السكنية ونوع المؤسسة

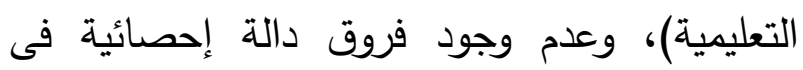

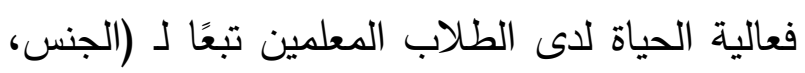
والمادة الاختيارية)

ד- هدفت دراسة (2016) Bloemhoff إلى تحديد أثر برنامج التعلم الخبراتى القائم على المغامرة على دراسل

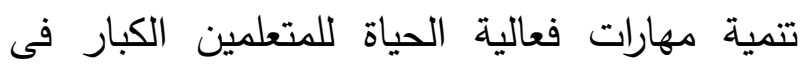
مدرسة إدارة الأعمال، وطبقت هذه الدراسة على هلى عينة مكونة من (TTY) متعلم بمدرسة إدارة الأعمال تم تقسيمه لمجموعتين مجموعة تجريبية تكونت من

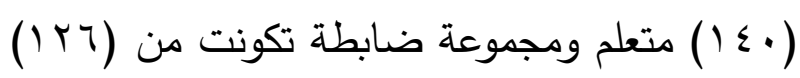

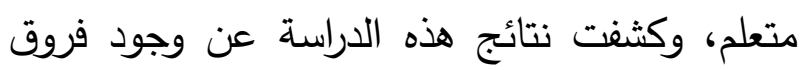
دالة إحصائية بين درجات الطلاب فى الاختبار

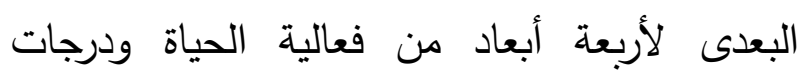
الطلاب فى الاختبار البعدى للمجموعة الضابطة،

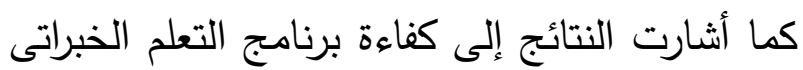

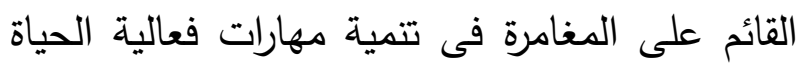

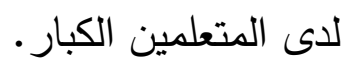

Cosmas, Seok\& Hashmi هدفت دراسة - V - ل (2016) إلى التعرف على الفروق بين الجنسين فى ثمانية مكونات من فعالية الحياة فى مرحلة ما قبل
مكونة من (דץ) طالبًا من طلاب الصف السادس

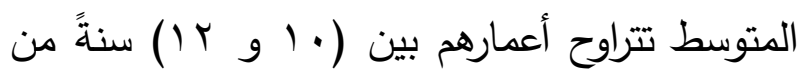
مدرسة متوسطة واحدة، وكثفت نتائج هذه الدراسة عن عدم وجود فروق دالة إحصائية بين درجات الطلاب فى القياس القبلى والقياس البعدى والقياس

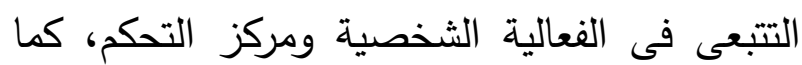
زاد بعد إدراك الذات لفعالية الحياة عند المشاركين فى البرنامج الصيفى لقيادة الإلهام عند الانتهاء

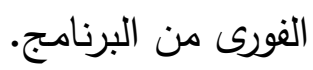
ع - هدفت دراسة Engeman (2013) إلى تطوير الخدمات والبنيات المجتمعية من خلال تعزيز الوعى العام نحو الأشخاص الذين يعانون من من فئن أمراض عقلية، وطبقت هذه الدراسة على عينة مكونة من (1/1) شخص تم تشخيص إصابتهم بأمراض عله عقلية وتم اختيارهم من عيادة الرعاية الصحية

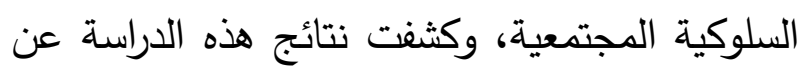
أن إدراك الفرد الذاتى لمهارات فعالية الحياة تؤثر هُه على التغيير الاجتماعى وذلك عن طريق مساعدة الأطباء لفهم العوامل المتعلقة بمدى قدرة الأفراد الذين يعانون من مرض عقلى على تطوير مهارات فعالية الحياة والعيش بشكل أكثر استقلالية.

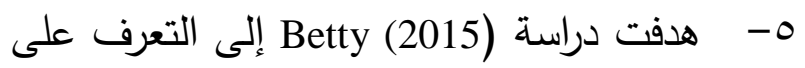
فعالية الحياة لدى الطلاب المعلمين للمرحلة الثانوية، ومقارنة فعالية الحياة للطلاب المعلمين للمرحلة الثانوية تبعًا لـ (النوع، والمنطقة السكنية، والمادة الاختيارية، ونوع المؤسسة التعليمية)، وطبقت هذه 
r- توجد علاقة دالة إحصائياً بين الحكمة ومهارات فعالية الحياة لدى طالبات جامعة القصيم. ب- لا توجد فروق دالة إحصائياً فى الحكمة واليقظة العقلية ومهارات فعالية الحياة لدى طالبات جامعة القصيم تبعاً لمتغير الفرقة الدراسية والتخصص. ع- يمكن التنبؤ باليقظة العقلية لدى طالبات جامعة القصيم من خلال درجاتهم فى الحكمة. 0- يمكن التنبؤ بمهارات فعالية الحياة لدى طالبات جامعة القصيم من خلال درجاتهم فى الحكمة. إجراءات البحث:1- منهج البحث:- نظراً لطبيعة البحث الحالي وأهدافه اعتمدت الباحثة على المنهج الوصفى حيث يستهدف هذا المنهج البحث والتقصي حول الظواهر التعليمية أو النفسية كما هي قائمة فى الحاضر ووصفها وصفاً دقيقاً وتشخيصها وتحليلها وتفسيرها بهدف اكتشاف العلاقات بين عناصرها أو بينها وبين الظواهر التعليمية والنفسية الأخري، ووبصفة خاصة

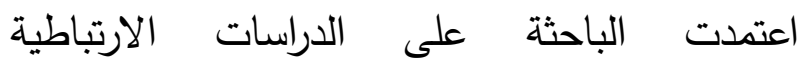
Correlation Method للكثف عن العلاقة الإرتباطية بين المتغيرات وتحديد قدر هذه العلاقة وإتجاهها. (العنيزى وسلامة

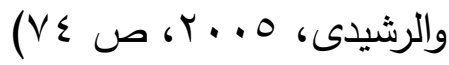

$$
\begin{aligned}
& \text { r - حدود البحث:- }
\end{aligned}
$$

- الحدود الزمنية:- تم تطبيق الثق الميداني لهذا البحث خلال الفترة الزمنية من؟؟؟؟؟؟؟؟؟؟ إلى
الدراسة وما بعدها، كما هدفت هذه الدراسة إلى قياس الفروق فى اتجاهات الشباب الريفى تجاه برنامج تطوير الثباب الإيجابى من خلال ثلاثة عوامل ديموغرافية (النوع، المستوى التعليمى، والمشاركة السابقة فى برامج الشباب)، وطبقت هذه الدراسة على عينة مكونة من (·r) شابًا ريفيًا تم تقسيمهم بواقع (9) ذكور أى بنسبة (0٪\%) و (11) أنثى أى (1) بنسبة (00\%) وبمتوسط عمر زمنى (10,1) عامًا وبانحراف معيارى قدره (1,1, ())، وكثفت نتائج هذه الدراسة عن وجود فروق ذات دلالة إحصائية بين الذكور والإناث فى فعالية الحياة وثلاثة من مكوناتها (الدافع للإنجاز ، المرونة الفكرية، والقيادة) فى مرحلة ما قبل الدراسة، ووجود علاقة ارتباطية دالة إحصائية بين الذكور والإناث فى المرونة الفكرية، وعدم وجود فروق ذات دلالة إحصائية فى الاتجاهات نحو برنامج تطوير الثباب الإيجابى بالنسبة للجنس، ومستوى التعليم، والمشاركة السابقة فى برامج الشباب. كما وجد أن الإناث أكثر حماسًا فى المشاركة عن الذكور، لأنهم منفتحين على أفكار جديدة، وقادرين على قيادة المجموعة عن الذكور • فروض البحث: بعد الاراسة النقدية للإطار النظري والدراسات السابقة يُمكن للباحثة صياغة الفروض الآتية:1- توجد علاقة دالة إحصائياً بين الحكمة واليقظة العقلية لدى طالبات جامعة القصيم. 
للبحث من (YVI) طالبة بجامعـة القصيم بمتوسط

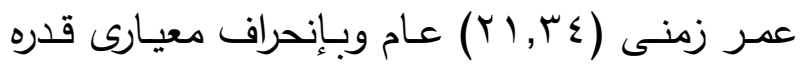

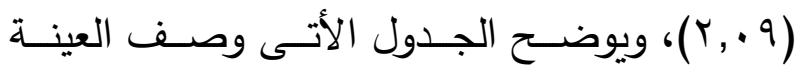
الأساسية للبحث.
• الحدود المكانية:- تم تطبيق الثق الميداني لهذا البحث بجامعة ؟؟؟؟؟؟؟؟؟ بمنطقة؟؟؟؟؟؟؟؟ ب- بينة البحث:تكونت العينـة الاستطلاعية للبحث من عدد (TV) طالبة بجامعة القصيم، كذلك تكونت العينة الأساسية جدول (1) وصف العينة الأساسية للبحث

\begin{tabular}{|c|c|c|c|}
\hline النسبة المئوية & العدد & \multicolumn{2}{|c|}{ المتغيرات } \\
\hline$\%$ \%r,q & 174 & الفرقة الأولى & \multirow{3}{*}{ الفرق الدراسية } \\
\hline$\%$ \%४,६Y & 91 & الفرقة الثانية & \\
\hline$\%$ \%q, זr & $1 \leqslant V$ & الفرقة الثالثة & \\
\hline$\% 1 \ldots$ & rvi & \multicolumn{2}{|c|}{ المجموع الكلى } \\
\hline$\% \circ 4, \wedge \vee$ & ril & علمى & \multirow{2}{*}{ التخصص الدراسى } \\
\hline$\% \leq r, 1 r$ & 17. & أدبى & \\
\hline$\% 1 \ldots$ & rVI & \multicolumn{2}{|c|}{ المجموع الكلى } \\
\hline
\end{tabular}

السعودية والمصرية (ملحق ؟) وتراوحت نسب اتفاق

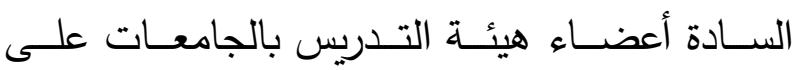

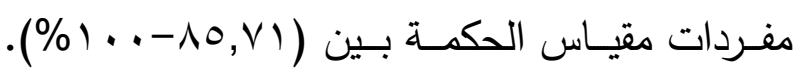

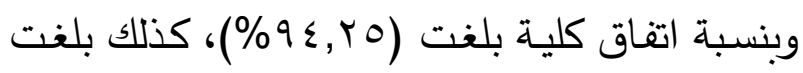

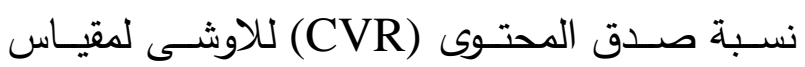

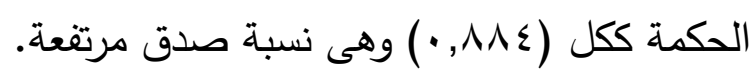

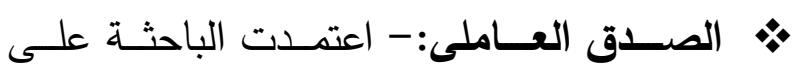
التحليل العاملى الاستكشافى Exploratory factor Principal بطريقة المكونات الأساسية Analysis Components Method الفاريماكس Varimx Meth ، وكثفت نتائج التحليل

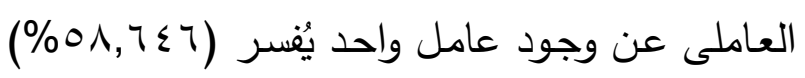

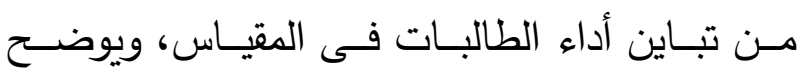

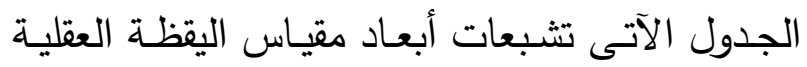
على العامل العام الناتج من التحليل العاملى.
צ- أدوات البحث:-

أ- مقياس الحكمة:- (إعداد/ الباحثة)

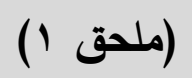

(1) الهدف من المقياس ووصفه:-

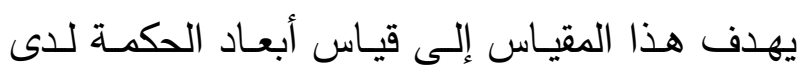

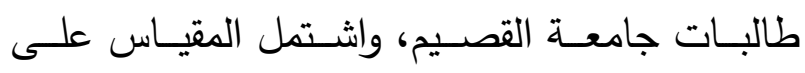

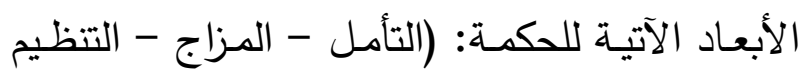

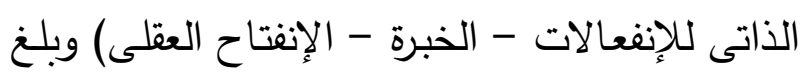
عدد المفردات المُخصصة لكل بعد من هذه الأبعاد

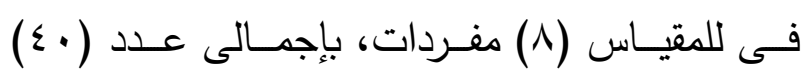
مفردة، وجميع المفردات موجبة. (Y) صدق المقياس:- مغدة، وحئ المغردات

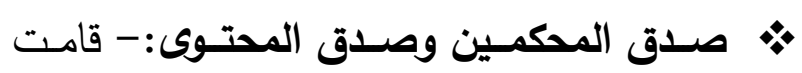
الباحثة بعرض المقياس على عدد (V) من أسـاتذة

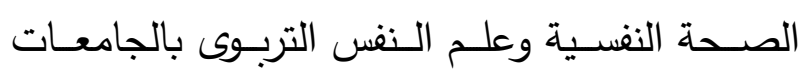




\begin{tabular}{|c|c|c|}
\hline & قليمة العامل التشبع & البعد \\
\hline & $\cdot, 00 r$ & التأمل. \\
\hline & $\cdot, 0 \leq 9$ & المزاج. \\
\hline & $\cdot, O Y$. & التنظيم الذاتى للإنفعالات \\
\hline & .,OMI & الخبرة. \\
\hline & •, & الإنقتاح العقلى. \\
\hline
\end{tabular}

\section{الثبات باستخدام طريقة ألفا كرونباخ:- قامت}

الباحثة بحساب ثبات مقياس الحكمة باستخدام طريقة

ألفا كرونباخ، والنتائج يوضحها الجدول الآتى:-

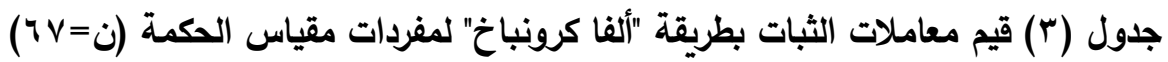

\begin{tabular}{|c|c|c|c|c|c|c|c|}
\hline معامل & المفردة & الثبات & المفردة & معامل & المفردة & الثبات & المفردة \\
\hline$\cdot, \vee 71$ & r & $\cdot, \vee Y \wedge$ & $r 1$ & $\cdot, \vee \vee \vee$ & 11 & $\cdot, \nabla \wedge Y$ & 1 \\
\hline$\cdot, V \vee r$ & $r r$ & $\cdot, \vee \vee 4$ & YY & $\cdot, \vee \vee \wedge$ & Ir & $\cdot, \vee \vee 79$ & $r$ \\
\hline -, 879 & $r r$ & $\cdot, V \vee I$ & $r r$ & $\cdot, V Y$. & 14 & $\cdot, V \leq \leq$ & $r$ \\
\hline$\cdot, \nabla r$. & $r \varepsilon$ & י & $r \varepsilon$ & $\cdot, v \leq r$ & $1 \varepsilon$ & $\cdot, \vee \vee q$ & $\varepsilon$ \\
\hline$\cdot, \vee \curlyvee \wedge$ & ro & $\cdot, V \otimes r$ & ro & $\cdot, \vee \wedge \diamond$ & 10 & $\cdot, \vee \vee \vee \varepsilon$ & 0 \\
\hline$\cdot, \vee \vee 0$ & rq & $\cdot, V Y r$ & YY & $\cdot, V R r$ & 17 & $\cdot, V 17$ & 7 \\
\hline$\cdot, \vee \vee \vee 0$ & $r v$ & $\cdot, 874$ & $r V$ & $\cdot, \vee \vee \vee$ & IV & $\cdot, V Y Y$ & $\mathrm{~V}$ \\
\hline$\cdot, v \leq q$ & $r \wedge$ & $\cdot, V \otimes V$ & $r \wedge$ & $\cdot, \nabla \vee r$ & 11 & $\cdot, V \otimes r$ & $\Lambda$ \\
\hline$\cdot, V \leq Y$ & rq & $\cdot, V \vee$. & rq & $\cdot, \vee \vee \vee \neg$ & 19 & $\cdot, \vee \wedge \wedge$ & 9 \\
\hline$\cdot$, VIr & $\varepsilon$. & $\because, \vee \vee 0$ & $r$. & - , VYI & $r$. & $\cdot, V \leqslant V$ & 1. \\
\hline
\end{tabular}

ويتضح من الجدول السابق أن مفردات مقياس الحكمة يقل معامل ثباتها عن قيمة معامل ثبات المقياس ككل

\section{( ) ( طريقة تصحيح المقياس:-}

تم تصديح المقياس وفقًا لتدريج ليكرت السداسى،

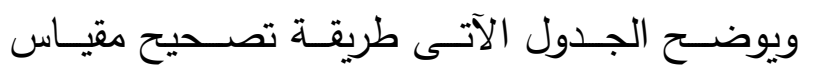

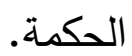

والذى بلغ (ع • م, •).

\section{الثبات باسـتخدام طريقـة إعـادة التطبيق: -}

قامت الباحثة بحساب ثبات مقياس الحكمة باستخدام

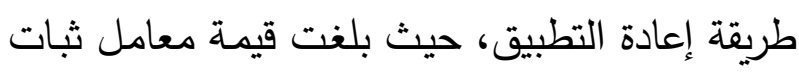

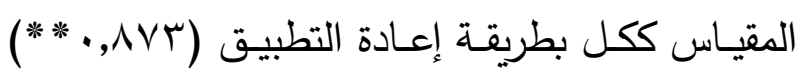

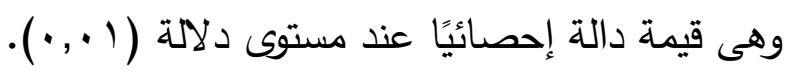


جدول (ء) طريقة تصحيح مقياس الحكمة

\begin{tabular}{|c|c|c|c|c|c|c|}
\hline \multicolumn{6}{|c|}{ خيارات الإجابة } & \multirow[b]{2}{*}{ المتغيرات } \\
\hline بثدافير & متروبئ & ضبرجة ضوافق & ضبرجة & متورجة موافي & موافقي & \\
\hline 1 & $\bar{r}$ & $r$ & $\varepsilon$ & 0 & 7 & المفردات الموجبة. \\
\hline \multicolumn{6}{|c|}{$r \leqslant$} & النهاية العظمى للمقياس \\
\hline \multicolumn{6}{|c|}{$\varepsilon}$. & النهاية الصغرى للمقياس \\
\hline
\end{tabular}

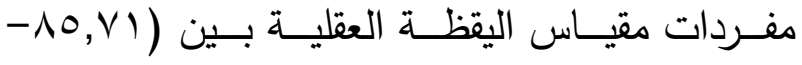

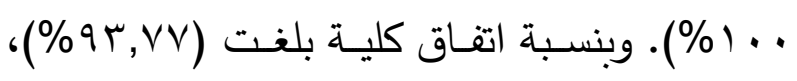
كذلك بلغت نسبة صدق المحتوى (CVR) للاوشى

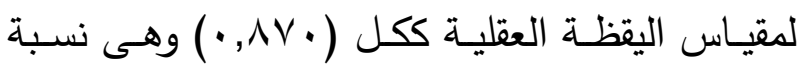
صدق مرتفعة.

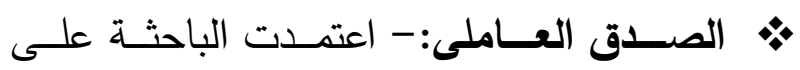
التحليل العاملى الاستكشافى Exploratory factor Principal بطريقة المكونات الأساسية الاسنية Analysis Components Method الفاريماكس Varimx Meth ، وكثفت نتائج التحليل

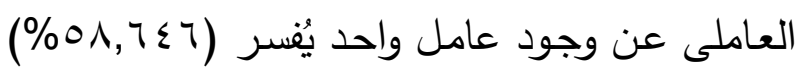

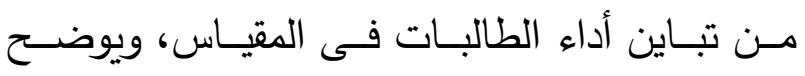
الجدول الآتى تثبعات أبعاد مقيساس اليقظة العقلية على العامل العام الناتج من التحليل العاملى.
ب- مقياس اليقظة العقلية:- (إعداد/ الباحثة) (ملحق r (r)

\section{(1) الهدف من المقياس ووصفه:-}

يهدف هذا المقيـاس إلى قياس اليقظة العقليـة للدى طالبات جامعة القصيم، واقتصر هذا المقياس على لئ لئل ثلاثة أبعاد لليقظة العقلية، وهى (الانتباه والملاحظة

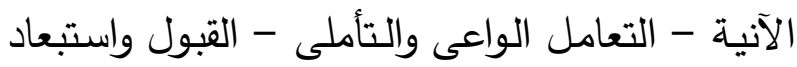
الحكم) وبلغ عدد المفردات المُخصصة لكل بعد من الدهايه هـذه الأبعـاد فـى الصــورة الأوليـة للمقيـاس (• (1)

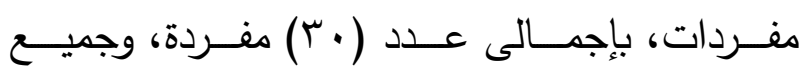
المفردات موجبة ما عدا (†) مفردات سالبة تُصحح

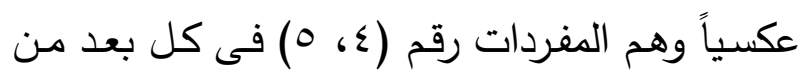

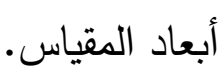
(Y) صدق المقياس: صـدق المحكمين وصـــق المحتـوى:- قامـت الباحثة بعرض المقياس على عدد (V) من أسـاتذة

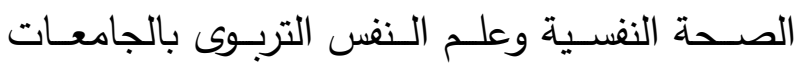
السعودية والمصرية (ملحق ع) وتراوحت نسب اتفاق

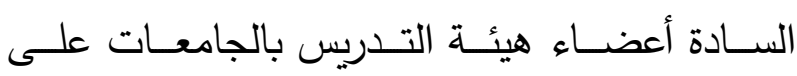




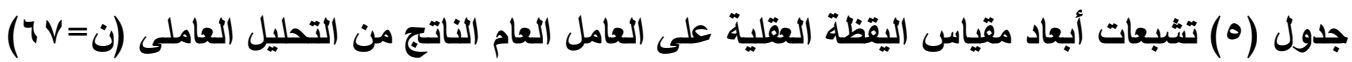

\begin{tabular}{|c|c|}
\hline قيمة التشبع على العامل العام & البعد \\
\hline$\cdot, 094$ & الاتتباه والملاحظة الآنية. \\
\hline$\cdot, 0 \wedge r$ & التعامل الواعى والتأملى. \\
\hline$\cdot, 0 \wedge \wedge$ & القبول واستبعاد الحكم. \\
\hline
\end{tabular}

ويتضح من الجدول السابق أن أبعاد مقياس اليقظة العقلية أظهرت تشبعات زادت قيمتها عن (•r, ·) على العامل الوحيد الناتج من التحليل العاملى، ولذلك فهى تثبعات دالة إحصائيًا. طريقــة ألفـا كرونبــاخ، والنتــائج يوضــحها الجـدول (ب) الثبات باستخدام طريقة ألفا كرونباخ:- قامت الآتى:الباحثة بحساب ثبات مقياس اليقظة العقلية باستخدام

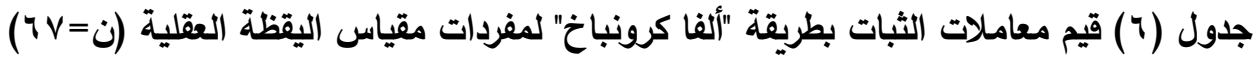

\begin{tabular}{|c|c|c|c|c|c|}
\hline معامل & المفردة & الثبات & المفردة & الثبات & المفردة \\
\hline$\cdot, \vee \wedge \varepsilon$ & ri & $\cdot, \mathrm{V} \vee$. & 11 & $\cdot, \vee \vee 0$. & 1 \\
\hline rד, & YY & • & Ir & -, $\vee 79$ & r \\
\hline$\cdot, v \leqslant r$ & rr & $\cdot, \vee \sim \Delta$ & ir & $\cdot, V \leq 0$ & $r$ \\
\hline$\cdot, \mathrm{V} \leqslant \Lambda$ & $r \leq$ & $\cdot, v \leq r$ & $1 \varepsilon$ & $\cdot, \vee \vee q$ & $\varepsilon$ \\
\hline$\cdot, v \leqslant 0$ & ro & \& & 10 & $\cdot, V \leq 4$ & 0 \\
\hline . , & צ & $\cdot, V \neg V$ & 17 & $\bullet, \vee \leq$. & 7 \\
\hline • & $r V$ & $\cdot, \vee \vee Y$ & IV & $\cdot, V \otimes V$ & V \\
\hline$\cdot, \vee \vee$. & r^ & $\cdot, \vee \vee \neg$ & 11 & $\cdot, \diamond \vee \leq$ & $\wedge$ \\
\hline$\cdot, V \leq 1$ & rq & $\cdot, V \mu$. & 19 & $\cdot, \mathrm{VT}$. & 9 \\
\hline . & $r$. & ., $\vee \vee q$. & $r$. & $\cdot, v \leq 0$ & 1. \\
\hline
\end{tabular}

ويتضح من الجدول السابق أن مفردات مقياس اليقظة العقلية يقل معامل ثباتها عن قيمة معامل ثبات المقياس ككل والذى بلغ

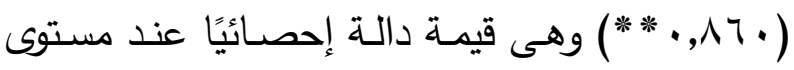
الثبات باسـتخدام طربقـة إعـادة التطبيق: :-

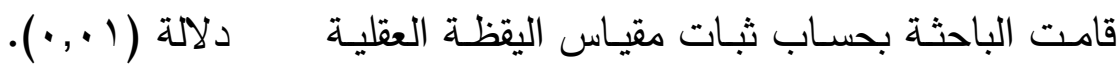
باسـتخدام طريقـة إعـادة التطبيقت، حيـث بلغـت قيمـة معامـل ثبات المقيـاس ككل بطريقــة إعـادة التطبيقت 
تم تصـيح المقيـاس وفقًا لتدريج ليكرت الخامسى، (ع ) طريقة تصحيح المقياس:ويوضتح الجدول الآتى طريقة تصحيح مقياس اليقظة

العقلية.

جدول (V) طريقة تصحيح مقياس اليقظة العقلية

\begin{tabular}{|c|c|c|c|c|c|}
\hline \multicolumn{5}{|c|}{ درجة التوافر } & \multirow{2}{*}{ المتغيرات } \\
\hline ضعيفة جداً & ضعيفة & متوسطة & كبيرة & كبيرة جداً & \\
\hline 1 & $r$ & $\mu$ & $\varepsilon$ & 0 & المفردات الموجبة. \\
\hline 0 & $\varepsilon$ & $r$ & $r$ & 1 & المفردات السالبة. \\
\hline \multicolumn{5}{|c|}{10.} & النهاية العظمى للمقياس \\
\hline \multicolumn{5}{|c|}{$r}$. & النهاية الصغرى للمقياس \\
\hline
\end{tabular}

الصــحة النفسـية وعلـم الـنفس التربـوى بالجامعـات السعودية والمصـرية (ملحق ع) وبلغت نسب اتفاق ج- مقياس مهارات فعالية الحياة:-- (إعداد) الفيل

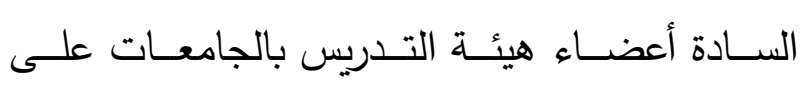
19 • r تعديل الباحثة). مفـردات مقيـاس مهـارات فعاليـة الحيـاة تتـراوح بـين لين (ملحق r)

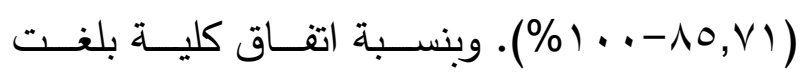

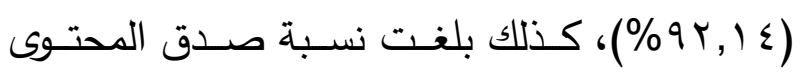
للاوشى لمقياس مهارات فعالية الحياة ككل (CVR) (109, • • ) وهى نسبة صدق مرتفعة. الصدق العاملى:- اعتمدت الباحثة على التحليل Exploratory factor Analysis العاملى الاستكثافى بطريقة المكونات الأساسية Principal Components Method Varimx Meth

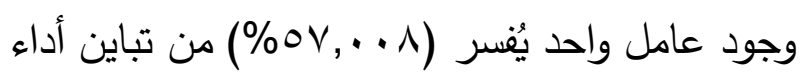
الطالبـات فـى المقيـاس، ويوضــح الجـدول الآتـى ولى

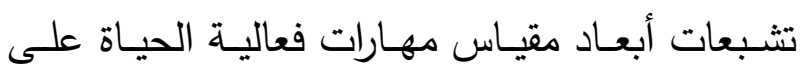
العامل العام الناتج من التحليل العاملى.

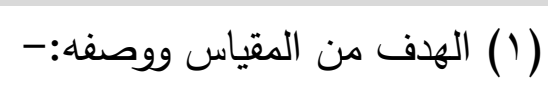
أعد هذا المقياس الفيل عام (9 1 ـ (Y) وقامت الباحثة بتعديلـه لكى يلائم البيئة السـعودية، ويهـدف هـذا المقياس إلى قياس مهارات فعالية الحياة لدى طالبات جامعـة القصيم، واقتصـر هذا المقيـاس على ثمانيـة مهارات لفعاليـة الحيـاة وهى (إدارة الوقت - الكفاءة الاجتماعيـة - دافعيـة الإنجـاز - المرونـة العقليـة قيـادة المهمـة - الـتحكم فـى الوجـدانات - المبـادرة النشــطة - الثقــة بـالنفس) وبلــن عـدد المفـردات المُخصصة لكل مهارة من هذه المهارات فى الصورة الأوليسة للمقيـاس (0) مفردات، بإجمالى عدد ( • ع) مفردة.

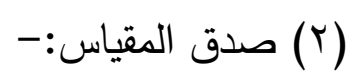
صـدق المحكمـين وصـدق المحتـوى:- قامـــ الباحثة بعرض المقياس على عدد (V) من أسـاتذة 


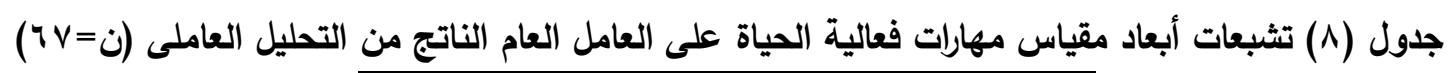

\begin{tabular}{|c|c|}
\hline قيمة التشبع على العامل العام & البعد \\
\hline$\cdot$, orr & إدارة الوقت. \\
\hline$\cdot, 0.9$ & الكفاءة الاجتماعية. \\
\hline$\cdot, \varepsilon \wedge$. & الدافعية للإنجاز. \\
\hline$\cdot, 0 \leq \leqslant$ & المرونة العقلية. \\
\hline., $07 \pi$ & قيادة المهام. \\
\hline., 001 & التحكم في الوجدانـات. \\
\hline$\cdot, \leqslant 9 V$ & المبادرة النشطة. \\
\hline •,OH. & الثقة بالنفس. \\
\hline
\end{tabular}

ويتضح من الجدول السابق أن أبعاد مقياس مهارات فعالية الحياة أظهرت تشبعات زادت قيمتها عن (•r,·•) على العامل الوحيد

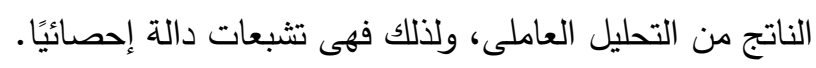

باسـتخدام طريقــة ألفـا كرونبـاخ، والنتـائج يوضـحها (r) ثبات المقياس:- (r)

• الثبات باسـتخدام طريقـة ألفـا كرونبـاخ:- قام الجدول الآتى:الباحث بحساب ثبات مقيـاس مهارات فعالية الحياة

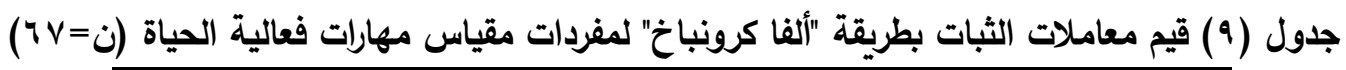

\begin{tabular}{|c|c|c|c|c|c|c|c|}
\hline الثبات & المفردة & الثبات & المفردة & الثبات & المفردة & الثبات & المفردة \\
\hline$\cdot, \vee \vee Q$ & r & - , VYr & YI & - , $\vee 7 \varepsilon$ & 11 & - , V० & 1 \\
\hline$\cdot, \vee \leq \Lambda$ & $M r$ & $\cdot, v 01$ & Yr & - , Vo. & $1 Y$ & - , $\vee \varepsilon$ & $r$ \\
\hline$\cdot, \vee \bullet$. & $r \mu$ & - , $\vee 7 \varepsilon$ & $r r$ & $\cdot, \vee \neg r$ & 14 & - , VPq & $\mu$ \\
\hline$\cdot, \vee \vee 71$ & rq & $\cdot, \vee \circ 7$ & $Y \varepsilon$ & $\cdot, \times 71$ & $1 \varepsilon$ & •, $\vee 7$. & $\varepsilon$ \\
\hline$\cdot, \vee \vee 7$. & ro & $\cdot, \vee \leq \Lambda$ & ro & $\cdot, V \leq V$ & 10 & - , VYo & 0 \\
\hline$\cdot, \vee \neg \wedge$ & rq & - , $v \circ 1$ & $r q$ & - , $\vee 7$. & 17 & - , V०. & 7 \\
\hline$\cdot, \vee \vee 0$ & $\mu v$ & $\cdot, \vee Y r$ & $r V$ & $\cdot, V \varepsilon \varepsilon$ & 18 & $\cdot, \vee \leq 0$ & $V$ \\
\hline$\cdot, V \leq r$ & $\mu \wedge$ & $\cdot, \vee \vee$. & $r A$ & . , Vo. & 11 & $\cdot, V \leq q$ & $\Lambda$ \\
\hline$\therefore, 17$. & rq & $\cdot, \vee \vee V$ & rq & $\cdot, \vee \leq \Lambda$ & 19 & $\therefore, \vee 0$. & 9 \\
\hline$\cdot, V \leq r$ & $\varepsilon$. & $\cdot, V M$. & $r$ & $\cdot, 870$ & $r$. & $\cdot, V \leq q$ & 1. \\
\hline
\end{tabular}

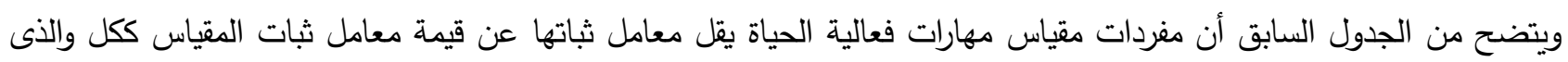

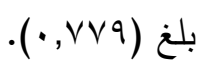

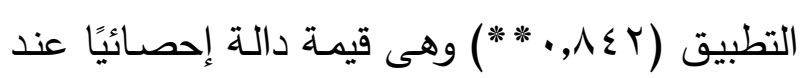
مستوى دلالة (1 • . •).
الثبـات باسـتخدام طريقـة إعـادة التطبيق:-

قامـت الباحثة بحسـاب ثبـات مقيـاس مهارات فعاليـة الحياة باستخدام طريقـة إعـادة التطبيق، حيث بلغت قيمـة معامـلـ ثبـات المقيـاس ككـل بطريقــة إعـادة 
تم تصحيح المقياس وفقًا لتدريج ليكرت الخامسى،

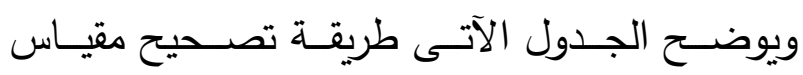

مهارات فعالية الحياة.

جدول (· 1) طريقة تصحيح مقياس مهارات فعالية الحياة

\begin{tabular}{|c|c|c|c|c|c|}
\hline \multicolumn{5}{|c|}{ خيارات الإجابة } & \multirow{2}{*}{ المتغيرات } \\
\hline أبدًا & نادرًا & أحيانًا & غالبًا & دائمًا & \\
\hline 1 & $r$ & $r$ & $\varepsilon$ & 0 & المفردات \\
\hline \multicolumn{5}{|c|}{$r \ldots$} & النهاية العظمى للمقياس \\
\hline & & $\varepsilon$ & & & النهاية الصغرى للمقياس \\
\hline
\end{tabular}

1- اختبار الفرض الأول:-

ينص على أنه "توجد علاقة دالة إحصائياً بين العكمة واليقظة العقلية لاى طالبات جامعة

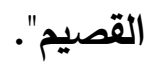

لاختبار صحة هذا الفرض استخدمت الباحثة معامل

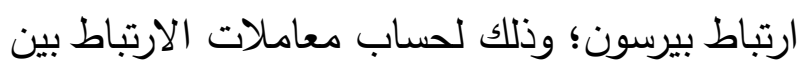
الحكمة واليقظة العقلية لدى طالبات جامعة القصيم، ودئل ويوضح الجدول الآتي المصفوفة الارتباطية بين الحكمة واليقظة العقلية لدى طالبات جامعة القصيم.
نتائج البحث ومناقثتها وتفسيرها:-

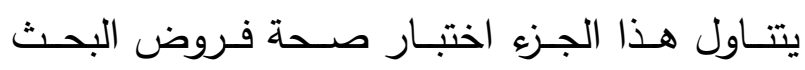

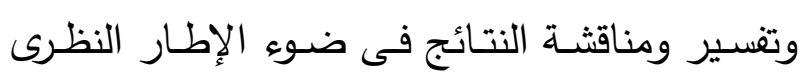

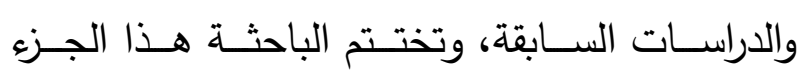

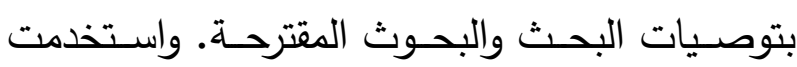
الباحثة في التحليل الإحصائي للبيانات حزمة البرامج

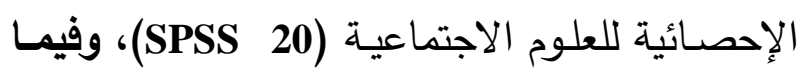
يلـي اختبـار فـروض البحـث وتفسـير ومناقثـة الإعة النتائج:-

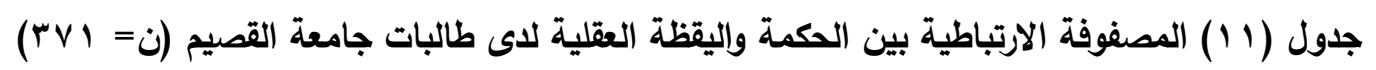

\begin{tabular}{|c|c|c|c|c|c|}
\hline \multicolumn{4}{|c|}{ اليقظة العقلية } & \multirow{2}{*}{\multicolumn{2}{|c|}{ المتفيرات }} \\
\hline الكجموع الكوع & و استبعاد الحكم & الواعى والتتاملي & و الملاحظة الآنبة & & \\
\hline $.323 * *$ & $.416^{* * *}$ & $.394 * *$ & $.117 *$ & التأمل. & \\
\hline $.242 * *$ & .074 & $.396 * *$ & $.236 * *$ & المزاج. & \\
\hline $.526 * *$ & $.437 * *$ & $.555 * *$ & $.497 * *$ & التنظيم الأاتى للإنفعالات & وكה \\
\hline $.484 * *$ & $.309 * *$ & $.549 * *$ & $.516 * *$ & الخبرة. & \\
\hline $.391 * *$ & $.412 * *$ & $.458 * *$ & $.248 * *$ & الإنفتاح العقلى. & \\
\hline $.484 * *$ & $.415 * *$ & $.581 * *$ & $.388 * *$ & المجموع الكلى & \\
\hline
\end{tabular}

يتضح من الجدول السابق أنه توجد علاقة دالة إحصائياً عند مستوى دلالة (1 .,.) بين أبعاد الحكمة وأبعاد اليقظة العقلية لدى

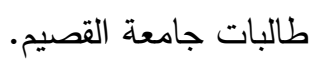


المواقف المختلفة يدل على تمتع الطالبة بأبعاد الحكمة؛ وعليه وجدت علاقات دالة إحصائياً عند مستوى دلالة (1 (., •) بين أبعاد الحكمة وأبعاد اليقظة العقلية لدى طالبات جامعة القصيم.

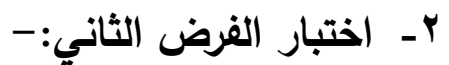
ينص على أنه "توجد علاقة دالة إحصائياً بين الحكمة ومهارات فعالية الحياة لاى طالبات جامعة

(القصيم".

لاختبار صحة هذا الفرض استخدمت الباحثة معامل ارتباط بيرسون؛ وذلك لحساب معاملات الارتباط بين الحكمة ومهارات فعالية الحياة لدى طالبات جامعة القصيم، ويوضح الجدول الآتي المصفوفة الارتباطية بين الحكمة ومهارات فعالية الحياة لدى طالبات جامعة القصيم.
وتتفق هذه النتيجة مع نتيجة العديد من الدراسات مثل دراسة (2012) Hill\& Updegraff والتى كشفت نتائجها عن وجود علاقة موجبة دالة إحصائية بين اليقظة العقلية والتظيم الانفعالى. وتُرجع الباحثة هذه النتيجة إلى أنه لا يوجد تأمل كأحد أبعاد الحكمة- بدون انتباه وملاحظة فورية ومستمرة وتعامل واعى مع مكونات المواقف المختلفة من قبل الطالبة وهذا يُبلور أبعاد اليقظة العقلية، كما أن مزاج الطالبة وخبرتها وإنفتاحها العقلى كأبعاد مُمثلة لحكمة تؤثر وتتأثر بانتباهها ويقظتها ومشاركتها فى المواقف التى تعايشها كما تؤثر وتتأثر بمقدار تعامل الطالبة مع المواقف والمشكلات التى تواجهها فى بيئتها الأكاديمية والأسرية. كما ترى الباحثة أن قبول المواقف وتأجيل الحكم عليها كأحد أبعاد اليقظة العقلية والانتباه المستمر واليقظ للعلاقات بين عناصر الموقف ومكونات

جدول (r I) المصفوفة الارتباطية بين الحكمة ومهارات فعالية الحياة لاى طالبات جامعة القصيم (ن = IF)

\begin{tabular}{|c|c|c|c|c|c|c|c|c|c|c|}
\hline \multicolumn{9}{|c|}{ مهارات فعالية الحياة } & \multirow{2}{*}{\multicolumn{2}{|c|}{ المتغيرات }} \\
\hline المجموع & بالنفس & المبادرة & التوجدم في & قيادة & العرونة العزية & الإنجاز & الاجتماعية الكفاعة & الوقارة & & \\
\hline $.267 * *$ & $.208 * *$ & $.256 * *$ & $.254 * *$ & $.292 * *$ & $.272 * *$ & $.260 * *$ & $.286 * *$ & $.265 * *$ & التأمل. & \multirow{6}{*}{ الحكمة } \\
\hline $.406 * *$ & $.268 * *$ & $.399 * *$ & $.344 * *$ & $.441 * *$ & $.399 * *$ & $.418 * *$ & $.479 * *$ & $.435 * *$ & المزاج. & \\
\hline $.544 * *$ & $.440 * *$ & $.587 * *$ & $.503 * *$ & $.514 * *$ & $.579 * *$ & $.587 * *$ & $.521 * *$ & $.526 * *$ & للإنفعالات الأتى & \\
\hline $.465 * *$ & $.327 * *$ & $.457 * *$ & $.430 * *$ & $.415 * *$ & $.485 * *$ & $.521 * *$ & $.496 * *$ & $.512 * *$ & الخبرة. & \\
\hline $.283 * *$ & $.204 * *$ & $.273 * *$ & $.267 * *$ & $.301 * *$ & $.283 * *$ & $.286 * *$ & $.309 * *$ & $.294 * *$ & الإنفتاح العقلى. & \\
\hline $.431 * *$ & $.317 * *$ & $.431 * *$ & $.395 * *$ & $.433 * *$ & $.442 * *$ & $.452 * *$ & $.460 * *$ & $.445 * *$ & المجموع الكلى & \\
\hline
\end{tabular}

يتضح من الجدول السابق أنه توجد علاقة دالة إحصائياً عند مستوى دلالة (1 ., ·) بين أبعاد الحكمة ومهارات فعالية الحياة لدى طالبات جامعة القصيم. 
وتتاول الموضوع من وجهات نظر مختلفة، كما أن

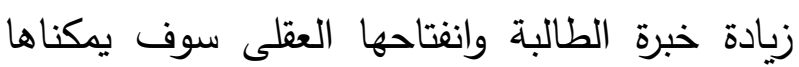
من قيادة الآخريات لتحقيق أهداف محددة وتحفيزهن كلما لزم الأمر وهذه المهارات تعكس بعض مهارات فعالية الحياة؛ وعليه وجدت علاقات دالة إحصائياً

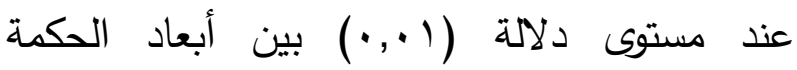
ومهارات فعالية الحياة لدى طالبات جامعة القصيم. r- اختبار الفرض الثالث:ينص على أنه "لا توجد فروق دالة إحصائياً فى الحى

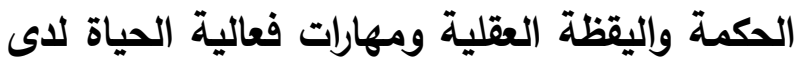
طالبات جامعة القصيم تبعاً لمتغير الفرقة الاراسية

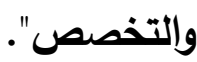

لاختبار صحة هذا الفرض استخدمت الباحثة تحليل Two - Way التباين الأحادى فى إتجاهين ANOVA العقلية ومهارات فعالية الحياة لاى طالبات جامعة القصيم تبعاً لكتغير الفرقة الدراسية والتخصص. والنتائج يوضحها الجدول الآتى:-
وتُرجع الباحثة هذه النتيجة إلى أنه التأمل والتنظيم الذاتى للإنفعالات والخبرة كأبعاد للحكمة من شانه أن أن يؤثروا فى مهارة إدارة الوقت لدى الطالبة حيث يُزيد

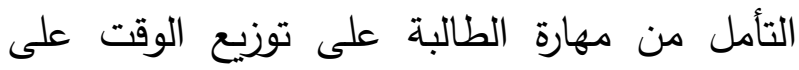

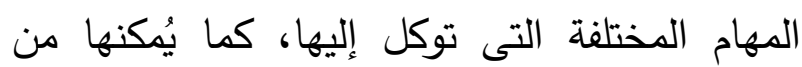
إدارة وقتها بثكل جيد ويساعدها على استثماره ولانتهاء من الأعمال فى الوقت المُخصص لها.

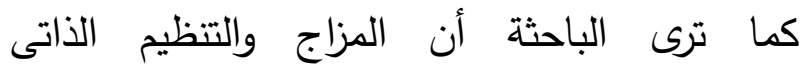
للإنفعالات كبعدين للحكمة من شأنهما أن يساعدا

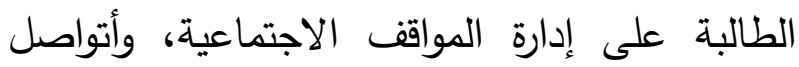
بشكل جيذ مع الناس، والتأثير فى الآخرين، كذلك الدئه سوف يساعداها على حل المشكلات الاجتماعية،

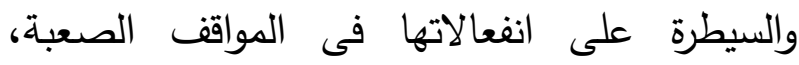
والثعور بالاطمئنان عند أداء المهام المختلفة وهذه المهارات تعكس بعض مهارات فعالية الحياة. كذلك ترى الباحثة أن الخبرة والإنفتاح العقلى كبعدين

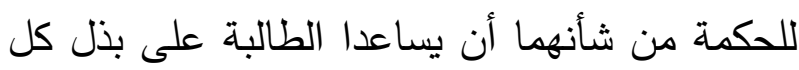

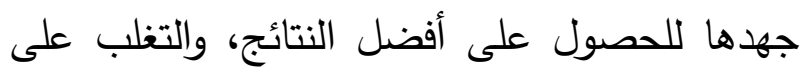
العقبات، كما سيزيدا من إصرارها ومثابرتها عند أداء عهاء المهام، وسيمكناها من تقبل وجهات نظر الآخرين،

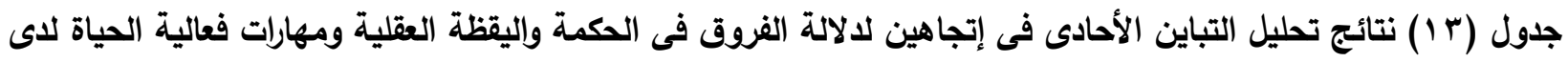
طالبات جامعة القصيم تبعاً لمتفير الفرقة الدراسية والتخصص (ن = (FV)

\begin{tabular}{|c|c|c|c|c|c|c|}
\hline مستولة الالاكي & قيمة (ف) & متروسط & الحرجية & المربعات & مصدر الخلاف & المتغيرات \\
\hline غير دالة & 2.486 & 377.541 & 2 & 755.081 & الفرقة الدراسية (أ) & \multirow{4}{*}{ الحكمة } \\
\hline 0.05 & 6.004 & 911.664 & 1 & 911.664 & التخصص (ب) & \\
\hline & & 151.848 & 367 & 55728.104 & الخطأ & \\
\hline & & & 371 & 8226938.000 & الكلى & \\
\hline
\end{tabular}




\begin{tabular}{|c|c|c|c|c|c|c|}
\hline غير دالة & 2.234 & 108.111 & 2 & 216.222 & الفرقة الدراسية (أ) & \multirow{4}{*}{ العقلية } \\
\hline \multirow[t]{3}{*}{ غير دالة } & 2.734 & 132.295 & 1 & 132.295 & التخصص (ب) & \\
\hline & & 48.391 & 367 & 17759.542 & الخطأ & \\
\hline & & & 371 & 2549460.000 & الكلى & \\
\hline غير دالة & .963 & 417.917 & 2 & 835.834 & الفرقة الدراسية (أ) & \multirow{4}{*}{ فهالية } \\
\hline \multirow[t]{3}{*}{ غير دالة } & .000 & .030 & 1 & .030 & التخصص (ب) & \\
\hline & & 434.048 & 367 & 159295.575 & الخطأ & \\
\hline & & & 371 & 4454298.000 & الكلى & \\
\hline
\end{tabular}

يتضح من الجدول السابق أنه لا توجد فروق دالة إحصائياً عند مستوى دلالمة (0. . ·) فى الحكمة واليقظة العقلية ومهارات فعالية

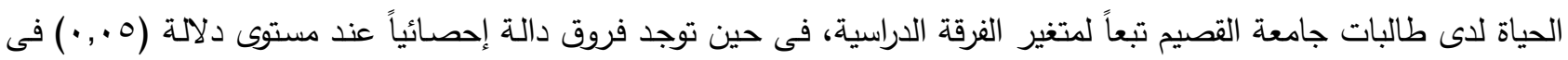

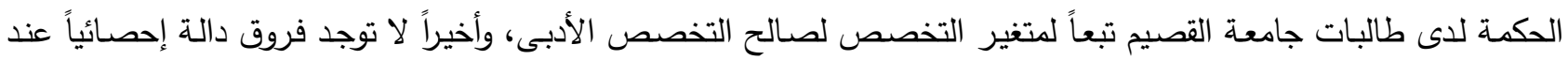
مستوى دلالة (0. . •) فى الحكمة لدى طالبات جامعة القصيم تبعاً لـتغير التخصص. ويوضـح الجدول الأتى المتوسطات الحسابية والإنحرافات المعياريـة لإدراك مخاطر الإنترنت بين بين الأسر وفقاً لمهنة الأم. جدول (؛ 1) المتوسطات الحسابية والإنحرافات المعيارية لدرجات طالبات جامعة القصيم فى الحكمة واليقظة العقلية ومهارات

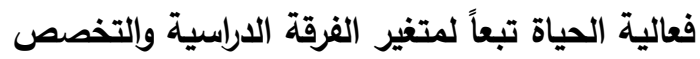

\begin{tabular}{|c|c|c|c|c|c|c|c|c|}
\hline \multicolumn{2}{|c|}{ مهارات فعالية الحياة } & \multicolumn{2}{|c|}{ اليقظة العقلية } & \multicolumn{2}{|c|}{ الحكمة } & \multirow{3}{*}{ 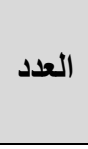 } & \multirow{3}{*}{\multicolumn{2}{|c|}{ المتغيرات }} \\
\hline الإنحراف & المتوسط & الإنحراف & المتوسط & الإنحراف & المتوسط & & & \\
\hline & الحسا & المعيارى & الحسك & المعيارى & & & & \\
\hline 20.36 & 105.79 & 6.74 & 82.64 & 10.53 & 148.52 & $1 \times 4$ & القرقة الأولى & \multirow{3}{*}{ الفرق الدراسية } \\
\hline 19.94 & 109.72 & 6.92 & 83.34 & 13.43 & 147.82 & $१ \wedge$ & الفرقة الثاتية & \\
\hline 21.72 & 107.70 & 7.20 & 82.08 & 13.16 & 148.69 & $1 \leqslant V$ & الفرقة الثالثة & \\
\hline 20.53 & 107.37 & 6.84 & 82.74 & 11.64 & 147.75 & rll & علمى & \multirow{2}{*}{ التخصص الدراسى } \\
\hline 21.23 & 107.87 & 7.16 & 82.43 & 13.27 & 149.25 & 17. & أدبى & \\
\hline
\end{tabular}

وثُرجع الباحثة عدم وجود فروق دالة إحصائياً فى الحياة لدى الطالبات قد يتطلب فترة زمنية أول

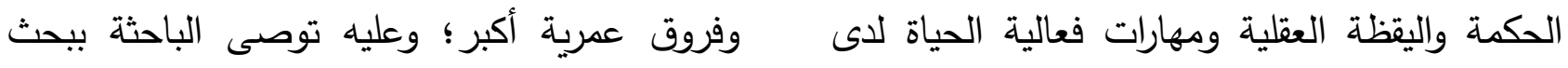
طالبات جامعة القصيم تبعاً لمتغير الفرقة الدراسية الفروق فى الحكمة واليقظة العقلية ومهارات فعالية إلى أن الطالبات على الرغم من اختلاف فرقتهم الحياة لدى الطالبات فى مراحل دراسية وأعمار زمنية الدراسية إلا أنهم يعايشون نفس البيئة الثقافية كما مختلفة. أنهم تخرجوا من نظام تعليمى واحد ودرسن نفس فى حين تُرجع الباحثة وجود فروق دالة إحصائياً فى

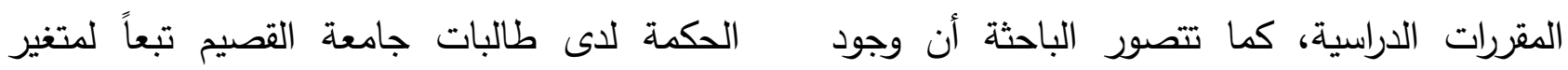
فروق فى الحكمة واليقظة العقلية ومهارات فعالية التخصص لصالح التخصص الأدبى إلى إختلاف 
طبيعة المواد الدراسية التى درسها فى التخصصين وللتحقق من صحة هذا الفرض استخدمت الباحثة

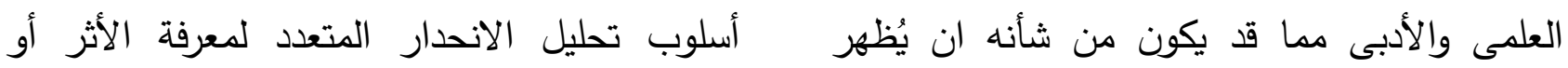
فروقاً فى مقدار تأمل وخبرة ومزاج الطالبات العلاقة بين أبعاد المتغيرات التفسيرية (أبعاد الحكمة)

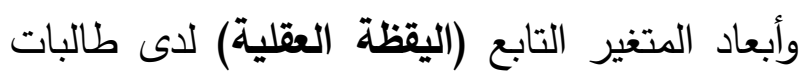
وانفتاحهن العقلى وكل هذا يُمثل أبعاد الحكمة. جامعة القصيم من خلال تقدير هذه العلاقة. والنتائج

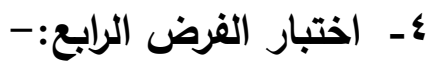

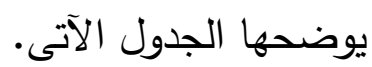

ينص على أنه "يمكن التنبؤ باليقظة العقلية لاى الهرص طالبات جامعة القصيم من خلال درجاتهم فى لمن لـن الحكمة".

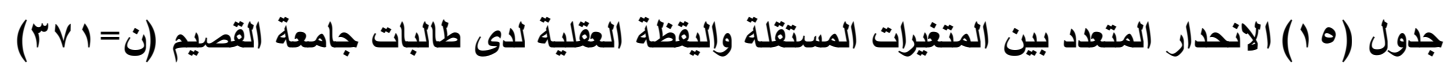

\begin{tabular}{|c|c|c|c|c|c|}
\hline الارتباط المتعدد & $\begin{array}{c}\text { التفسير معامل } \\
\mathbf{R}^{2}\end{array}$ & الاتحدار & الاتحدار & المتغير التابع & المتغيرات المستقلة \\
\hline \multirow{5}{*}{$\cdot, 794$} & \multirow{5}{*}{$\%\{\wedge, 1$} & -1.513 & \multirow{5}{*}{33.835} & \multirow{5}{*}{ العقلية } & التأمل \\
\hline & & -1.403 & & & المزاج \\
\hline & & 1.542 & & & التنظيم الأاتى للإنفعالات \\
\hline & & .508 & & & الخبرة \\
\hline & & 2.483 & & & الإنقتاح العقلى \\
\hline
\end{tabular}

وتشُير قيمة (R2) فى الجدول السابق إلى نسبة النسبة المتبقية من التباين ترجع إلى متغيرات أخرى (البواقي) لم تؤخذ في الاعتبار في معادلة الانحدار.

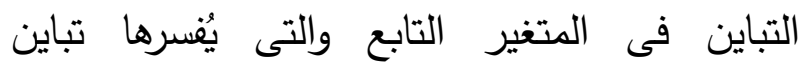

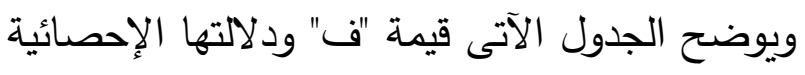

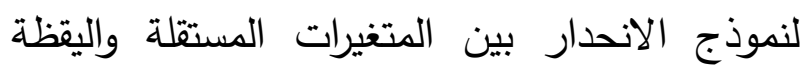
المتغيرات المستقلة؛ وهذا يعني أن (أبعاد الحكمة) العقلية.

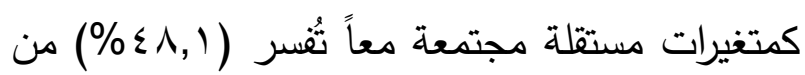

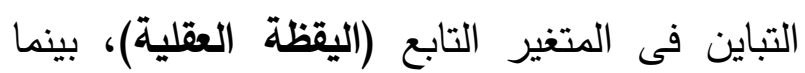
جدول (1 1 ) قيمة "ف" ودلالتها الإحصائية لنموذج الانحدار بين المتغيرات المستقلة واليقظة العقلية لاى طالبات

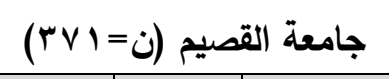

\begin{tabular}{|c|c|c|c|c|c|}
\hline الدلالة & "فيمة & المربعات & الدرجية & مجموع المربعات & مصدر الاختلاف \\
\hline \multirow{3}{*}{., .1} & \multirow{3}{*}{67.623} & 1729.707 & 5 & 8648.533 & الانحدار \\
\hline & & 25.579 & 365 & 9336.222 & البواقي \\
\hline & & & 370 & 17984.755 & الكلى \\
\hline
\end{tabular}

يتضح من الجدول السابق أن قيمة "ف" دالة إحصائياً؛ مما يُشير إلى أن المتغيرات الدستقلة وهي (أبعاد الحكمة) تؤثر بدرجة دالة الدئ

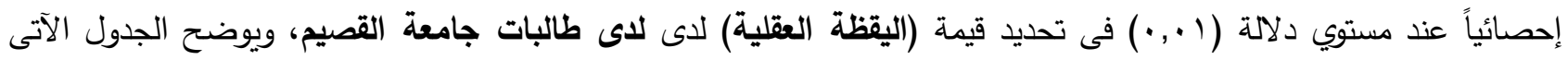
ملخص تحليل الانحدار المتعدد. 


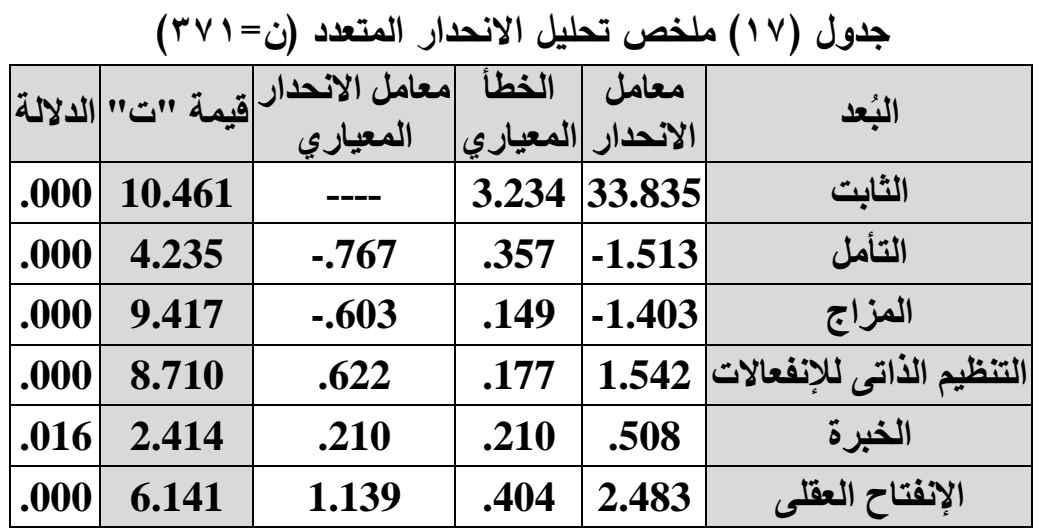

ويضضح من الجدول السابق أن قيمة "ت" للمقدار الثابت لمعامل الانحدار دالة إحصائياً عند مستوى (1.....) كما أن معامل

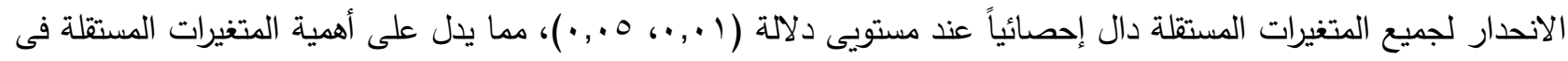
التتبؤ باليقظة العقلية لاى طالبات جامعة التصيم. ويشير معامل الانحدار إلى العلاقة بين المتغيرات المتعدد التي تعين على التتبؤ باليقظة العقلية لدى بلى المستقلة (أبعاد الحكمة) والمتغير التابع (اليقظة طالبات جامعة القصيم كالتالي:العقلية)، وعليه يمكن صياغة معادلة الانحدار

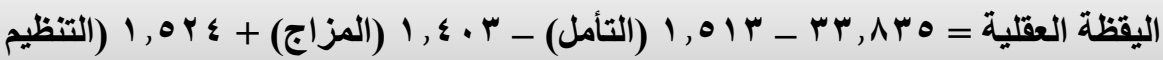

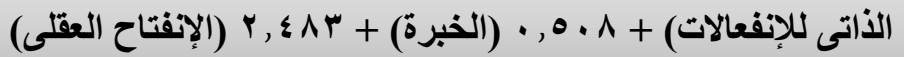

ولتحديد أهم المتغيرات المستقلة إسهاماً فى التتبؤ الانحدار المتتابع Stepwise Regression والنتائج باليقظة العقلية قام الباحث بتحليل الانحدار باستخدام يوضحها الجدول الآتي:-

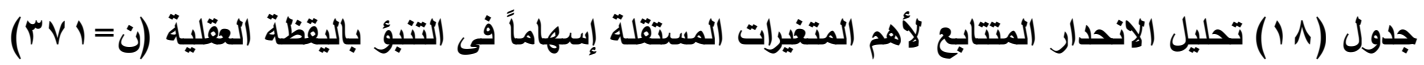

\begin{tabular}{|c|c|c|c|c|}
\hline معامل التفسير R & الانحدار & الانحدار & المتغير التابع & المتغير المستقل \\
\hline$\% r v, q$ & $1, r \cdot \varepsilon$ & $\{0,0 Y \leqslant$ & اليقظة العقلية & اللإنظفعالات الأتى \\
\hline
\end{tabular}

ومن الجدول السابق يتضح أن إسهام بعد التنظيم يمكن صياغة معادلة الانحدار المتعدد التي تعين الأتى للإنفعالات فى تنسير التباين فى اليقظة على التنبؤ باليقظة العقلية من خلال بعد التنظيم

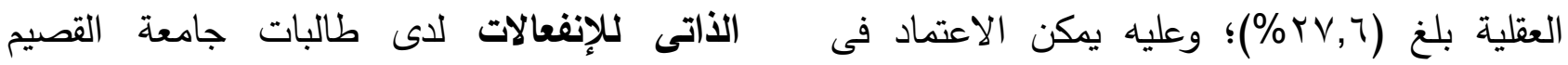
التتبؤ باليقظة العقلية على بعد التنظيم الذاتى كالتالى:للإنفعالات لأنه الأكثر إسهاماً فى تفسيرها. وبالتالي لئلي 


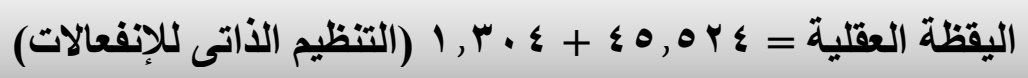

المواقف المختلفة، كذلك يؤثروا فى قدرة الطالبة على التكيف مع المواقف المختلفة ويساعداها على التمتع بالمرونة فى المواقف المفاجئة والطارئة؛ وعليه يمكن التتبؤ باليقظة العقلية لدى طالبات جامعة القصيم من خلال درجاتهم فى الحكمة. هـ - اختبار الفرض الخامس:ينص على أنه "يمكن التنبؤ بمهارات فعالية الحياة

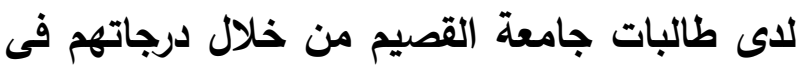

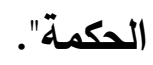
وللتحقق من صحة هذا الفرض استخدمت الباحثة أسلوب تحليل الانحدار المتعدد لمعرفة الأثر أو العلاقة بين أبعاد المتغيرات التفسيرية (أبعاد الحكمة)

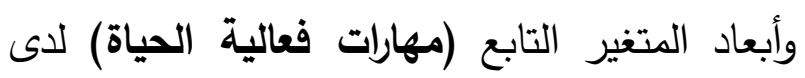
طالبات جامعة القصيم من خلال تقدير هذه العلاقة. والنتائج يوضحها الجدول الآتى.
وتتفق هذه النتيجة مع نتيجة العديد من الدراسات

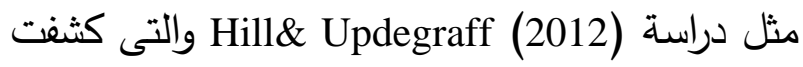
عن وجود علاقة دالة إحصائياً بين التتظيم الانفعالى كأحد أبعاد الحكمة واليقظة العقلية. وتُرجع الباحثة هذه النتيجة إلى أنه التأمل والتنظيم الذاتى للإنفعالات والمزاج والخبرة والانفتاح العقلى

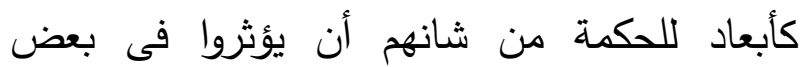
مؤشرات اليقظة العقلية لاى الطالبة مثل انتباه الطالبة لتأثير البيئة المحيطة عليها، وقدرتها على لئى ملاحظة التقاصيل الدقيقة فى المواقف المختلفة، وتتظيم انتباهها كذلك التيقظ لكل ما يدور حولها، كما أن التأمل والتتظيم الذاتى للإنفعالات والمزاج

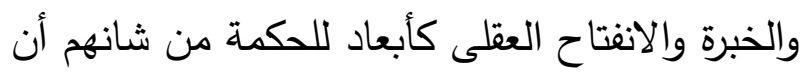
يؤثروا فى قدرة الطالبة على قراءة جميع متطلبات الموقف الذى تتواجد فيه وفهم العلاقات غير المرئية فى المواقف وإدراك التاثيرات المتبادلة بين عناصر

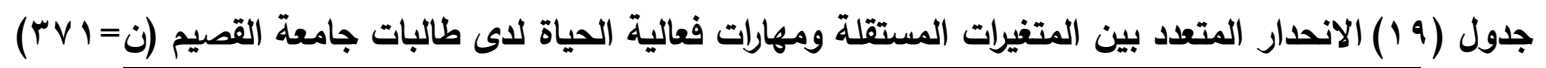

\begin{tabular}{|c|c|c|c|c|c|}
\hline الارتباط المتعدد & $\begin{array}{c}\text { التفسير معامل } \\
\mathbf{R}^{2}\end{array}$ & الاتحدار & الانحدار & المتغير التابع & المتغيرات المستقلة \\
\hline \multirow{5}{*}{$\cdot, 00 \leqslant$} & \multirow{5}{*}{$\% \omega \cdot, v$} & -.213 & \multirow{5}{*}{11.760} & \multirow{5}{*}{ فهالية } & التأمل \\
\hline & & -.516 & & & المزاج \\
\hline & & 3.817 & & & التنظيم الأتى للإنفعالات \\
\hline & & .656 & & & الخبرة \\
\hline & & -.311 & & & الإنفتاح العقلى \\
\hline
\end{tabular}

وتُشير قيمة (R2) فى الجدول السابق إلى نسبة المتغيرات المستقلة؛ وهذا يعني أن (أبعاد الحكمة)

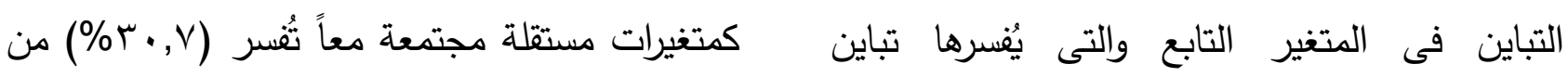


الانحدار • ويوضح الجدول الآتى قيمة "ف" ودلالتها الإحصائية لنموذج الانحدار بين المتغيرات المستقلة ومهارات فعالية الحياة.

التباين فى المتغير التابع (مهارات فعالية الحياة)، بينما النسبة المتبقية من التباين ترجع إلى متغيرات

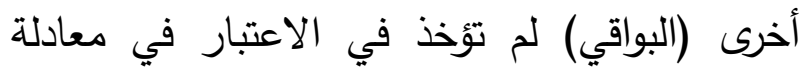
جدول (·r) قيمة "ف" ودلالتها الإحصائية لنموذج الانحدار بين المتغيرات المستقلة ومهارات فعالية الحياة لاى طالبات جامعة فئة القصيم (ن= (rVI)

\begin{tabular}{|c|c|c|c|c|c|}
\hline الدلالة & "قَّمة & المربعات & الرجية & مجموع المربعات & مصدر الاختلاف \\
\hline \multirow{3}{*}{$\cdot, \cdot 1$} & \multirow{3}{*}{32.380} & 9240.589 & 5 & 46202.947 & الانحدار \\
\hline & & 285.376 & 365 & 104162.298 & البواقي \\
\hline & & & 370 & 150365.245 & الكلى \\
\hline
\end{tabular}

يتضح من الجدول السابق أن قيمة "ف" دالة إحصائياً؛ مما يُشير إلى أن المتغيرات المستقلة وهي (أبعاد الحكمة) تؤثر بدرجة دالة

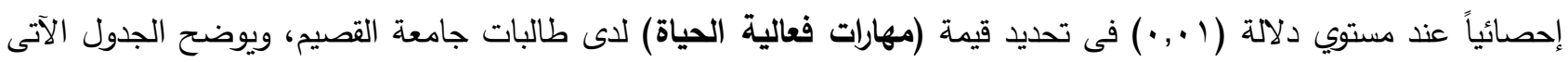
ملخص تحليل الانحدار المتعدد. جدول (Y (Y) ملغص تحليل الانحدار المتعدد (ن= = (YV)

\begin{tabular}{|c|c|c|c|c|c|}
\hline 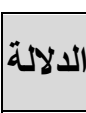 & |قيمة "ت" & معامل الآحدار & الفعياري & الانحارل & البُعد \\
\hline 161 & 1.406 & ---- & 8.365 & 11.760 & الثابت \\
\hline 878 & 154 & -.044 & 1.387 & -.213 & التأمل \\
\hline 375 & .889 & -.084 & .581 & -.516 & المزاج \\
\hline 000 & 5.449 & .590 & .701 & 3.817 & التنظيم الذاتى للإنفعالات \\
\hline .425 & .799 & .106 & .821 & .656 & الخبرة \\
\hline .838 & .204 & -.061 & 1.524 & -.311 & الإنفتاح العقلى \\
\hline
\end{tabular}

ويتضح من الجدول السابق أن قيمة "ت" للمقدار الثابت لمعامل الانحدار غير دالة إحصائياً عند مستوى (ه.,.•) في حين أن

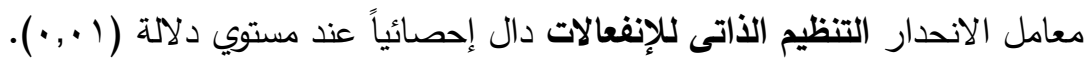

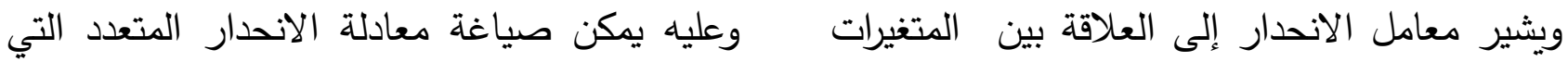

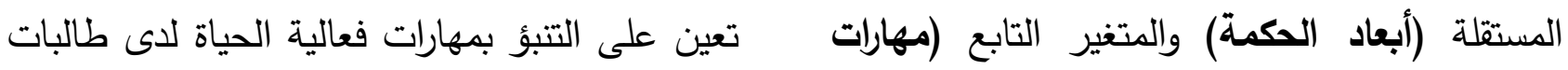
فعالية الحياة)، فيتضح أن أكبر متغير مستقل مرتبط جامعة القصيم كالتالي:-

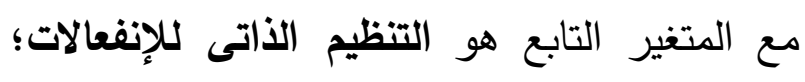

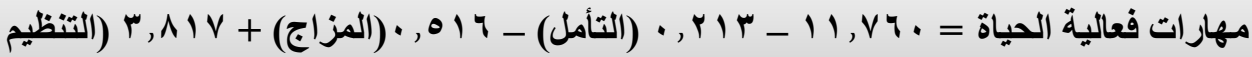

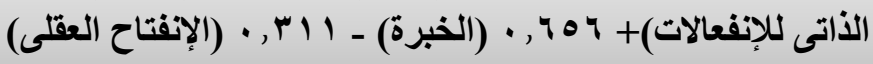


Stepwise Regression ولتحديد أهم المتغيرات المستقلة إسهاماً فى التتبؤ استخدام الانحدار المتتابع بمهارات فعالية الحياة قام الباحث بتحليل الانحدار والنتائج يوضحها الجدول الآتي:-

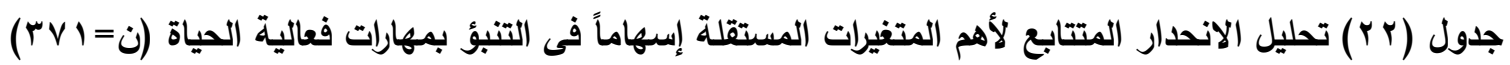

\begin{tabular}{|c|c|c|c|c|}
\hline معامل التفسير R & الانحدار & 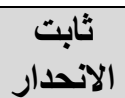 & المتغير التابع & المتغير المستقل \\
\hline$\%$ \%q, & $r, \Delta r \leq$ & $1, .97$ & فعالية & التتظيم الأاتى للإنفعالات \\
\hline
\end{tabular}

ومن الجدول السابق يتضح أن إسهام التظظيم الذاتى يمكن صياغة معادلة الانحدار المتعدد التي تعين للإنفعالات فى تفسير التباين فى مهارات فعالية على التتبؤ بمهارات فعالية الحياة من خلال بعد

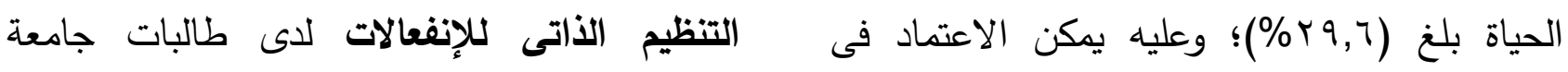
التتبؤ بمهارات فعالية الحياة على التظيم الأتى القصيم كالتالى:للإنفعالات لأنها الأكثر إسهاماً فى تفسيرها. وبالتالي

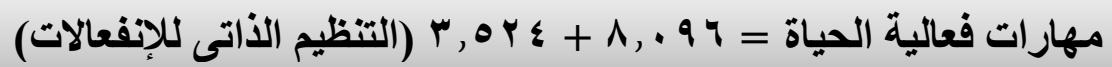

وتُرجع الباحثة هذه النتيجة إلى أنه التأمل والتنظيم زيادة خبرة الطالبة وانفتاحها العقلى كبعين للحكمة الذاتى للإنفعالات والخبرة كأبعاد للحكمة من شانهم سوف يمكنا الطالبة من السيطرة على الزميلات أن يؤثروا فى بعض مهارات فعالية الحياة مثل مهارة والتأثير فيهن الآخريات لتحقيق أهداف محددة إدارة الوقت ومهارة المبادرة والدافعية للإنجاز وقيادة وتحفيزهن كلما لزم الأمر؛ وعليه يمكن التنبؤ المهمة والثقة بالنفس كذلك سيؤثروا على ثقة الطالبة بمهارات فعالية الحياة لاى طالبات جامعة القصيم

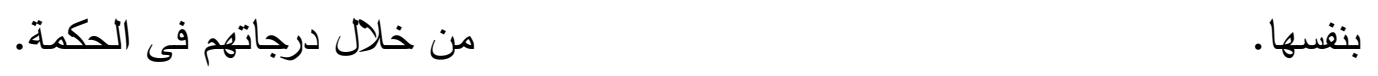
كما ترى الباحثة أن المزاج والتتظيم الذاتى توصيات ومقترحات البحث:للإنفعالات والخبرة والإنفتاح العقلى كأبعاد للحكمة - توجيه البرامج الإعلامية فى الجامعة وخارجها من شأنهم أن يساعدوا الطالبة على إدارة المواقف إلى توعية الطلاب بأهمية السلوكيات التى تتسم الاجتماعية، والتواصل بشكل جيد مع الناس، كذلك بالحكمة فى المواقف الحياتية المختلفة. سوف يساعدوا الطالبة بذل المزيد من الجهدها ب- تقديم ندوات مستمرة بالجامعة تتناول اليقظة للحصول على أفضل النتائج، والتغلب على العقبات، العقلية ومهارات فعالية الحياة فى حياتهم الأكاديمية وتتاول الموضوع من وجهات نظر مختلفة، كما أن والاجتماعية. 


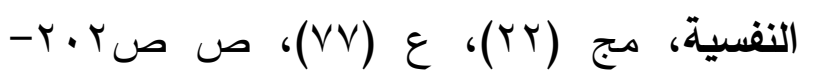
. $Y \leqslant$.

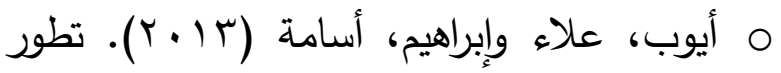
التفكير القائم على الحكمة لدى طلاب الجامعة بدول الخليج العربي "دراسة عبر ثقافية". المجلة المصرية

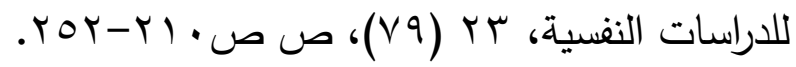

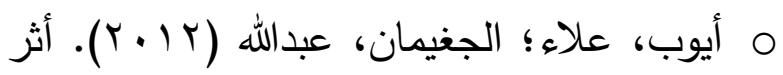
اكتساب الحكمة في تتمية التفكير الجدلي ومهارات اتخاذ القرار لدى طلاب جامعة الملك فيصل بالمملكة العربية السعودية. المجلة المصرية لعلوم المراهقة، 0، ص صع ب-9.7.

O بنى يونس، محمد محمود (V. . . (Y). سيكولوجيا الدافعية والانفعالات. دار الميسرة للنشر والتوزيع والطباعة، عمان: الأردن.

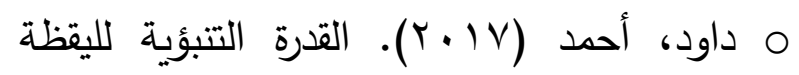
العقلية والتعاطف الذاتي بالخلل الوظيفي لدى مرضى الاكتئاب الرئيس. رسالة ماجستير، كلية الآداب والعلوم-جامعة عمان الأهلية. O شاهين، هيام (r ( ب (r). إسهام كل من الذكاء الاجتماعى وأحداث الحياة الضاغطة فى التنبؤ بالحكمة لدى معلمى مدارس التربية الفكرية. مجلة العلوم التربوية والنفسية، مج (r ا)، ع (r)، ص ص ص O الضبع، فتحى ومحمود، أحمد (r/ • (Y). فاعلية اليقظة العقلية فى خفض أعراض الاكتئاب النفسى لاى عينة من طلاب الجامعة. مجلة الإرشاد r- توفير المناخ الجامعى والأنشطة الجامعية التى تعزز أبعاد الحكمة اليقظة العقلية ومهارات فعالية

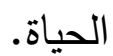
ع- إعداد برامج تدربيية لتنمية الحكمة واليقظة العقلية ومهارات فعالية الحياة لدى طلاب الجامعة. 0- ببحث الفروق فى الحكمة واليقظة العقلية ومهارات فعالية الحياة لدى الطالبات فى مراحل دراسية وأعمار زمنية مختلفة. T- إجراء بحث مشابه لهذا البحث على عينات أخرى وفى مناطق أخرى بالمملكة العربية السعودية. - V - Vذجة العلاقات البنائية بين اليقظة العقلية وجودة الحياة والرضا عن الحياة لدى طلاب وطالبات الجامعة. - - نمذجة العلاقات البنائية بين مهارات فعالية الحياة وجودة الحياة والرضا عن الحياة لدى طلاب

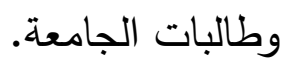

\section{المسراجحع}

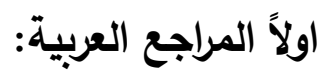

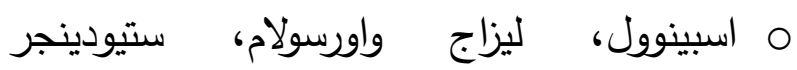

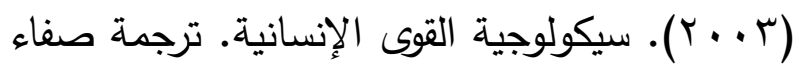
الأعسر وآخرون ... ... القاهرة: المجلس الأعلى للثقافة. O أيّوب، علاء الدين (Y ( ا (Y). أثر برنامج تدريبي لتنمية التفكير القائم على الحكمة في تحسين استراتيجيات المواجهة لحلّ المشكلات الضاغطة لدى طلاب الجامعة. المجلة المصرية للدراسات 
ومهارات فعالية الحياة لدى طلاب التربية الفنية بكلية التربية النوعية جامعة الإسكندرية. مجلة كلية التربية

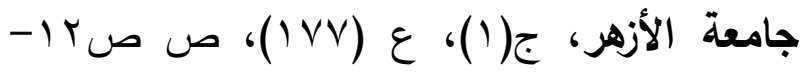
.$v T$

O الفيل، حلمى (9 ( ب). متغيرات تربوية حديثة على البيئة العربية (تأصيل وتوطين). القاهرة: مكتبة الأنجلو المصرية.

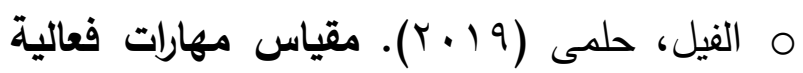
الحياة. القاهرة: مكتبة الأنجلو المصرية.

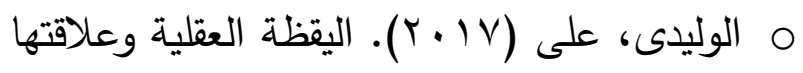
بالسعادة النفسية لدى طلاب جامعة الملك خالد.

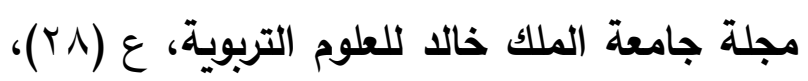

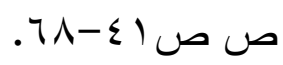
ثانياً المراجع الانجليزية

○ Achenbaum, W.A., \& Orwoll, L. (1991). Becoming wise: A psychogerontological interpretation of the book of Job. International Journal of Aging and Human Development, 32, 21-39.

○ Akcoltekin, A. (2015). High school students' time management skills in relation to research anxiety. Educational Research and Reviews, Vol. 10(16), pp. 2241-2249.

○ Al-Ghamdi, M. (2008): Time Management of Secondary Schools in Taif Managers, Educational Administration and Planning Department, Umm Al Qura University, Saudi Arabia.

○ Ambrosi-Randic, N\& Plavšic, M. (2015). The role of education in development of wisdom Educational Development Strategies in Different Countries and Regions of the World: National, Regional and Global Levels. Quality, Social Justice and Accountability in
النفسى صادرة عن مركز الارشاد النفسى، ع(؟؟)،

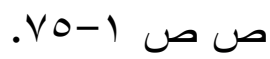
O عزيز، شادية وقاسم، سندسو كريم، دعاء

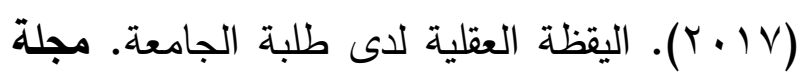
كلية التربية-جامعة القادسية. م العنيزى، يوسف وسلامة، سمير والرشيدى، عبد

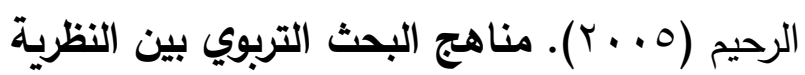
والتطبيق. الكويت: مكتبة الفلاح للنشر والتوزيع. م العنيزى، يوسف وسلامة، سمير والرشيدي، عبد الرحيم (0. . ب). مناهج البحث التربوي بين النظرية والتطبيق. الكويت: مكتبة الفلاح للنشر والتوزيع.

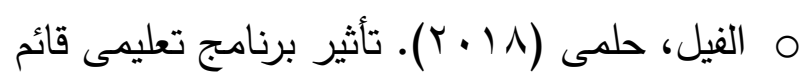

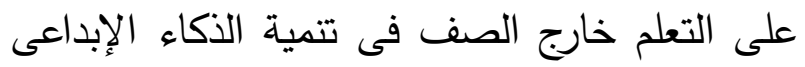
Education Worldwide. BCES Conference Books, Volume 13, Number 2, PP11-17.

○ Ardelt, M\& Jeste, D. (2018). Wisdom and Hard Times: The Ameliorating Effect of Wisdom on the Negative Association between Adverse Life Events and Well-Being. The Journals of Gerontology: Series B, Volume 73, Issue 8, PP1374-1383.

○ Ardelt, M. (2004). Wisdom as expert knowledge system: A critical review of a contemporary operationalization of an ancient concept. Human Development, 47(5), 257285.

○ Armbruster, D. J. N., Ueltzhöffer, K., Basten, U., \& Fiebach, C. J. (2012). Prefrontal Cortical Mechanisms Underlying Individual Differences in Cognitive Flexibility and Stability. Journal of Cognitive Neuroscience, 24(12), 2385-2399.

○ Baltes, P. B \& ،.Smith, J. (2008). The fascination of wisdom: Its nature ontogeny, 
and function. Perspectives on Psychological Science, 3(1), 56-64 .

○ Bergen-Cico, D \& Cheon, S. (2013). The Mediating Effects of Mindfulness and SelfCompassion on Trait Anxiety. Science+Business Media New York, PP1-15. ○ Betty, P. (2015). An Investigation about Life effectiveness of Student Teachers at Secondary Level. International Journal of Education and Psychological Research (IJEPR), 4(2), pp.17-19.

○ Bishop, S., Lau, M., Shapiro, S., Carlson, L., Anderson, N.\& Carmody, J. (2004) Mindfulness: A proposed operational definition. Clinical Psychology: Science and Practice, 11, 230-241.

○ Bloemhoff, H. (2016). Impact of One-Day Adventure-Based Experiential Learning (AEL) Program on Life Effectiveness Skills of Adult Learners. South African Journal for Research in Sport, Physical Education and Recreation, 38(2), PP27-35.

○ Brown, S., \& Greene, J. (2006). The wisdom development scale Translating the conceptual to the concrete. Journal of College Student Development, 47(1), 1-19.

○ Burleson, B. R. (2003). The experience and effects of emotional support: What the study of cultural and gender difference can tell us about close relationships, emotion, and interpersonal communication. Personal Relationships, 10, 1-23.

○ Çelik V (2002). Sınıf yönetimi. Ankara: Nobel Yayıncılık.

○ Cole, P.M., Martin, S.E., \& Dennis, T.A. (2004). Emotion regulation as a scientific construct:

o Coleman, P. K. (2003). Perceptions of parent-child attachment, social self-efficacy and peer relationships in middle childhood. Infant and Child Development, 12, 351-368.

- Cosmas, G., Seok, C\& Hashmi, S. (2016). Life Effectiveness and Attitude towards the Psy4life Programme. 4th Annual International
Conference on Cognitive - Social, and Behavioural Sciences, pp.18-28.

o Covey, S (2004). Business Masterminds (Translation: Alam Aldeen, ghasan).Riadh,Saudi Arabia.

○ Cyril, V. (2015). Time Management and Academic Achievement of Higher Secondary Students. i-manager's Journal on School Educational Technology, Vol. 101 No. 3 , PP38-43.

○ Dajani, D. R., \& Uddin, L. Q. (2015). Demystifying cognitive flexibility: Implications for clinical and developmental neuroscience. Trends in Neurosciences, 38(9), 571-578.

○ Engeman, T. (2013). Strategies for Coping with Mental Illnesses and Life Effectiveness. PhD Thesis, Walden University

○ Erözkan, A. (2013). İletişim becerileri ve kişilerarası problem çözme becerilerinin sosyal yetkinliğe etkisi. Kuram ve Uygulamada Ĕ̈itim Bilimleri, 13(2), 731-745.

○ Ferrari, M., \& Potworowski, G. (2008). Teaching for wisdom: cross-cultural perspectives on fostering wisdom. Springer.

○ Gedviliene, G. (2014). The case of Lithuania and Belgium: Teachers and students' social competence. European Scientific Journal, 10(13), 181-294.

○ Greene, J. (2009). The Wisdom Development Scale: Further Validity Investigations. Int'1. J. Aging and Human DEVELOPMENT, Vol. 68(4) 289-320.

○ Griffin, G. A. (1995). Influences of shared decision making on school and classroom activity: Conversations with five elementary teachers. The Elementary School Journal, 96(1), 29-45.

○ Gustafsson, B. (2010). Some thoughts on the relationship between knowledge and wisdom. Portland Press Limited. 
○ Halverson R., Grigg, J., Prichett, R., \& Thomas, C., (2006). The new instructional leadership: Crafting data-driven instructional systems in schools. Submitted January 17, 2006 to Journal of School Leadership.

- Halverson, R. (2003). Systems of practice: How leaders use artifacts to create professional community in schools. Education Policy Analysis Archives, 11(37).

- Halverson, R. (2006). A distributed leadership perspective on how leaders use artifacts to create professional community in schools. Wisconsin Center for Education Research.

○ Hendriana, H. (2012). Pembelajaran matematika humanis dengan metaphorical thinking untuk meningkatkan kepercayaan diri siswa. Infinity, 1(1), 90-103.

○ Hill, Ch\& Updegraff, J. (2012). Mindfulness and Its Relationship to Emotional Regulation. American Psychological Association, Vol. 12, No. 1, 81-90.

○ Holliday, S.G., \& Chandler, M.J. (1986). Wisdom: Explorations in adult competence. Basel, Switzerland: Karger.

○ Jordan, J. (2005). The quest for wisdom in adulthood: a psychological perspective. In R. J. Sternberg \& J. Jordan (Eds.), A handbook of wisdom. Psychological perspectives (pp. 160188). New York: Cambridge University Press. ○ Kabat-Zinn, J. (2003). Mindfulness-based interventions in context: Past, present, and future. Clinical Psychology: Science and Practice, 10, 144-156.

- MacCann, Carolyn; Fogarty, Gerard J.; Roberts, Richard D.(2012). Strategies for Success in Education: Time Management Is More Important for Part-Time than Full-Time Community College Students. Learning and Individual Differences, v22 n5 p618-623.

○ Magelinskaite, Š., Kepalaite, A., \& Legkauskas, V. (2014). Relationship between social competence, learning motivation, and school anxiety in primary school. ProcediaSocial and Behavioral Sciences, 116, 29362940.

○ Massanelli, N. (2016). Teaching Elementary Students Wisdom through Scaffolding in Collaborative Reasoning Groups. College of Education and Health Professions-University of Arkansas

- McCleod, B\& Craig, S. (2004). An Evaluation of Experiential Learning and Outdoor Education school programs on the life effectiveness skills of middle school boys. Andrew Brooks, Dr. Peter Martin (Chair). 114. Bendigo, Australia: LaTrobe University. Retrieved from http://www.latrobe.edu.au/education/download s/2004_conference_mcLeod.pdf

- McPheat, S. (2010). Personal confidence and motivation. London: MTD Training \& Ventus Publishing APS.

- McPheat, S. (2010). Personal confidence and motivation. London: MTD Training \& Ventus Publishing APS.

- Merrell, B. (2009). The Effect of Lift on Life Effectiveness and Locus of Control. PhD Thesis, Office of Graduate Studies of Texas A\&M University.

○ Mettler, J., Carsley, D., Joly, M\& Heath, N. (2017). Dispositional Mindfulness and Adjustment to University. Journal of College Student Retention: Research, Theory \& Practice.

○ Mickler, C., \& Staudinger, U. M. (2008). Personal wisdom: validation and age-related differences of a performance measure. Psychology and Aging, 23(4), 787-799.

○ Mosse, D. (2009). Outcomes of a Therapeutic Recreation Program on the Life effectiveness of Adolescents. Master Thesis, Southern Illinois University Carbondale

○ Neil, J., Marsh, H., \& Richards, G. (2003). The life effectiveness Questionnaire: 
development and psychometrics. Sydney: University of Western Sydney.

○ Neill, J. (2008). Resilience and outdoor education. Keynote presentation to the 1 st Singapore Outdoor Education Conference, Dairy Fair Adventure Centre, Singapore, November 5-6. Singapore.

$\circ$ Neill, J. (2008B). Enhancing Life Effectiveness: The Impacts of Outdoor Education Programs. PhD Dissertation, University of Western Sydney.

○ Neill, J., Marsh, H., \& Richards, G. (2003) .The Life Effectiveness Questionnaire: Development and Psychometrics. Unpublished manuscript, Sydney, Australia: University of Western Australia.

$\circ \mathrm{OH}$, H. (2013). Wisdom And The Life Course: An Analysis of Life Course Factors Related to Laypeople's Conceptions Of Wisdom. PHD dissertation, GRADUATE SCHOOL- FLORIDA UNIVERSITY.

○ Osvaldo, R. (2011). Human Resource Management in Strength Quality Prospective. Published McGraw Hill, New York.

○ Pennebaker, J. W. (1989). Confession, inhibition, and disease. In L. Berkowitz (Ed.), Advances in experimental social psychology, (Vol. 22. Pp. 211-244). Orlando, FL: Academic Press.

○ Pennebaker, J. W. (2002). Writing, social processes, and psychotherapy: From past to future. In S. J. Lepore \& J. M. Smyth. (Eds.), The writing cure: How expressive writing promotes health and emotional well-being (pp. 281-291). Washington, DC: American Psychological Association.

- Petri, H, and Govern, J (2004). Motivation Theory, Research and Applications. ThmsonWadworth, Australia.

○ Quickel, E., Johnson, S\& David, Z. (2014). Trait Mindfulness and Cognitive Task Performance Examining the Attentional Construct of Mindfulness. SAGE Journal Volume: 4 issue: 4 .
○ Randic, A\& Plavšic, N. (2015). Students' Wisdom Related Knowledge as Expertise. Education Provision to Every One: Comparing Perspectives from Around the World BCES Conference Books, 2016, Volume 14, Number 2, PP23-29.

○ Roháriková, V; Špajdel, M; Cviková, V\& Jagla, F. (2013). Tracing the relationship between wisdom and health. Act Nerv Super Rediviva; 55 (3), PP95-102.

- Sarıçam, H., Akın, A., Akın, U., \& Çardak, M. (2013). Algilanan sosyal yetkinlik ölçeğinin Türkçeye uyarlanması: Geçerlik ve güvenirlik çalışması. The Journal of Academic Social Science Studies, 6(3), 591-600.

- Sarıçam, H., Akın, A., Akın, U., \& Çardak, M. (2013). Algilanan sosyal yetkinlik ölçeğinin Türkçeye uyarlanması: Geçerlik ve güvenirlik çalışması. The Journal of Academic Social Science Studies, 6(3), 591-600.

- Sarıçam, H., Akın, A., Akın, U., \& Çardak, M. (2013). Algilanan sosyal yetkinlik ölçeğinin Türkçeye uyarlanması: Geçerlik ve güvenirlik çalışması. The Journal of Academic Social Science Studies, 6(3), 591-600.

- Sayan İ (2005). Yönetici Hemsirelerde Zaman Yönetimi. Yüksek Lisans Tezi. İstanbul. Marmara Üniversitesi.

- Sayan İ (2005). Yönetici Hemsirelerde Zaman Yönetimi. Yüksek Lisans Tezi. İstanbul. Marmara Üniversitesi.

- Shapiro, S. \& Carlson, L. (2009). The art and science of mindfulness: Integrating mindfulness into psychology and the helping professions. Washington, DC: American Psychological Association.

○ Shapiro, S., Carlson, L., Astin, J\& Freedman, B. (2006). Mechanisms of Mindfulness. Journal of Clinical Psychology, Vol. 62(3), 373-386.

○ Siegel, R. (2014). The Science of Mindfulness: A Research-Based Path to WellBeing . The Great Courses, PP1-545. 


$$
\text { جوهرة صالح المرشود }
$$

○ Spillane, J. (2005). Distributed leadership. The Educational Forum, 69, 143-149.

- Spillane, J. (2005). Distributed leadership. The Educational Forum, 69, 143-149.

○ Sternberg, R. J. (2001). Why schools should teach for wisdom: The balance theory of wisdom in educational settings. Educational Psychologist, 36(4), 227-245.

○ Ten-Dam, G., \& Volman, M. (2007). Educating for adulthood or for citizenship: Social competence as an educational goal. European Journal of Education, 42(2), 281298.

○ Ten-Dam, G., \& Volman, M. (2007). Educating for adulthood or for citizenship: Social competence as an educational goal. European Journal of Education, 42(2), 281298.

- Uğur A (2000). Çalısma hayatında zaman yönetimi. MPM Kalkınmada Anahtar Verimlilik Dergisi. 12(143):18-22.
- Uğur A (2000). Çalısma hayatında zaman yönetimi. MPM Kalkınmada Anahtar Verimlilik Dergisi. 12(143):18-22.

○ Verešová, M., Čerešník, M \& Malá, D. (2013). Differences in Life Satisfaction in Relation to Sense of Coherence of Future Teachers. Journal of Modern Education Review, 3 (11), pp.839-851.

○ Wang, Y., Xu, W \& Luo, F. (2016). Emotional Resilience Mediates the Relationship between Mindfulness and Emotion. Vol (118), issue (3), PP725-736.

○ Webster, J. (2003). An exploratory analysis of a self-assessed wisdom scale. Journal of Adult Development, 10, 13-22.

○ Webster, J. (2007). Measuring the character strength of wisdom. International Journal of Aging and Human Development, 65, 163-183. o Wink, P., \& Helson, R. (1999). Practical and transcendent wisdom: Their nature and some longitudinal findings. 
الإسهام النسبى لأبعاد الحكمة فى التنبؤ باليقظة العقلية ومهارات فعالية الحياة لدى طالبات جامعة القصيم

\title{
The Relative Contribution of Wisdom Dimensions to Prediction of Mindfulness and Life Effectiveness Skills among AIQassim University Female Students
}

\author{
Dr. Jawharah Saleh Almarshoud \\ Associate Professor - Psychology \\ College of Education Dammam \\ Psychology
}

\begin{abstract}
Research aimed at Identifying the relationship between Wisdom Dimensions and Mindfulness, Identifying the relationship between Wisdom Dimensions and Life Effectiveness Skills among AlQassim University Female Students, and Discovering the differences in the wisdom, Mindfulness and Life Effectiveness Skills among AlQassim University Female Students according to of class and specialization variable and Detecting the degree of the Relative Contribution of Wisdom Dimensions to Prediction of Mindfulness and Life Effectiveness Skills among AlQassim University Female Students.

And this Research applied on a sample consists of (371) University Female Students With average age (21.34) years and a standard deviation of (2.09). Researcher used Wisdom Scale (Prepared by Researcher), Mindfulness (Prepared by Researcher) and Life Effectiveness Skills (prepared by Elfiel (2019) editing by researcher), For Statistical Analysis researcher depend on Pearson correlation coefficient, multiple regression analysis method and Stepwise multiple regression.

The Results of the Research indicated That There is statistically significant relationship at the level of (0.01) between Wisdom Dimensions and Mindfulness, There is statistically significant relationship at the level of (0.01) between Wisdom Dimensions Life Effectiveness Skills among AlQassim University Female Students, There were no statistically significant differences at the level of significance (0.05) in the wisdom, Mindfulness and Life Effectiveness Skills among AlQassim University Female Students according to class variable, There were no statistically significant differences at the level of significance (0.05) in the Mindfulness and Life Effectiveness Skills among AlQassim University Female Students according to specialization variable and There is a statistically significant relative contribution at the level of (0.01) for Wisdom Dimensions to Prediction of Mindfulness and Life Effectiveness Skills among AlQassim University Female Students.

This Research Recommended by several recommendations such as providing workshops for university students specialized in training them on Mindfulness and Life Effectiveness Skills And Preparation of guidance and training programs to develop the wisdom, Life Effectiveness Skills for university students. Key words: Wisdom. Mindfulness. Life Effectiveness Skills.
\end{abstract}

